\title{
A Macroeconomic Perspective on Knowledge Management*
}

\author{
Mathias Thoenig - HEC Lausanne and CEPR \\ Thierry Verdier - Paris School of Economics and CEPR
}

November 25, 2009

\begin{abstract}
This paper provides a theory of the interactions between knowledge codification, firm-level organization structures, information diffusion and the dynamics of technological competition. At the firm level, we focus on incentives to design Knowledge Management policies based on the codification of soft into hard information. At the aggregate level, we discuss the endogenous nature of knowledge spillover and the implications for macroeconomic growth. The model predicts the existence of a bell shaped relationship between knowledge codification and technological competition.

JEL Codes: L14, L16, L23, O31, O40

Keywords: Codification, technological spillover, contracts, growth.
\end{abstract}

${ }^{*}$ We particularly thank Daron Acemoglu, Philippe Aghion, Eve Caroli, Pierre-Philippe Combes, Gene Grossman, Elhanan Helpman, David Martimort, Niko Matouschek, Frédéric Robert-Nicoud, David Sraer, Jean Tirole and participants at the CIAR Economic Growth \& Institutions meeting in Spain, IDEI (Toulouse), INSEE (Paris), CEPR Workshop on Globalization \& Firms Organizations and Oxford, for their helpful comments. All remaining errors are ours. 
"Evidence from research conducted since the mid-1960s shows that [...] managers get two thirds of their information to make decisions from face-to-face or telephone conversations; they acquire the remaining third from documents, most of which come from outside the organization", (Davenport, 1994, Harvard Business Review).

\section{Introduction}

Nowadays, Knowledge Management is receiving tremendous attention within companies and among business academics. ${ }^{1}$ A landmark study by OECD (2003) finds that Knowledge Management (KM) practices are by now a widespread phenomenon across countries, concentrated not only in high tech/knowledge-intensive industries but also in more traditional manufacturing industries. On the academic front, business gurus keep on stressing the importance of KM as a necessary tool to achieve competitiveness in the so-called "Knowledge-based Economy"2. Surprisingly, economists have so far paid little attention to this recent phenomenon.

Conceptually, KM is about " a range of practices used in an organisation to identify, create, represent, distribute and enable adoption of insights and experiences. Such insights and experiences comprise knowledge, either embodied in individuals or embedded in organisational processes or practice" (Wikipedia). Given the importance that information flows and knowledge have for innovation, market success and socioeconomic relationships, KM therefore leads naturally to a number of interesting and important economic questions. How should a firm manage the nature and diffusion of its informational flows in a given competitive environment? Should it codify its processes or should it rely on the existence of tacit knowledge? What are the macroeconomic implications for the dynamics of innovation and economic growth? In this paper, we provide a first theoretical attempt to discuss and understand these issues.

We emphasize the basic transformation of soft information into hard information. Typically, this transformation takes place through a codification process that systematically increases the transfer capacity of information across individuals. We identify a crucial trade-off: Codification of information enables verifiability by a third party and therefore allows the design of more explicit and efficient contracts within a given group of contracting agents; for the very same reason however, codification leads to increased possibilities of informational spillover to other third parties who might exploit these spillover to out-compete the initial contracting group. In this paper, we consider this trade-off within the context of innovating firms where contracting and transfer of information is important for efficient production. We investigate the aggregate consequences of this firm-level trade-off in term of organizational structures, dynamics of technological competition and macroeconomic growth. For

\footnotetext{
${ }^{1}$ In the business literature, there are at least 30 periodicals and magazines publishing articles, case studies and analyses on Knowledge Management (a good reference is the Knowledge Management Resource Center at http://www.kmresource.com).

${ }^{2}$ See for instance Peter Drucker (1999) or Thomas Davenport who claims that "Knowledge management has to be baked into the job. It's got to be part of the fabric of the work." (http://www.cio.com/archive/110199/think.html).
} 
this purpose, a standard Schumpeterian growth model with quality ladder a la Aghion and Howitt (1992) or Grossman and Helpman (1991) is coupled to a model of internal organization of the firm characterized by an endogenous dimension of contract incompleteness.

We consider a theoretical framework where success in R\&D competition depends crucially on informational spillover. At each date creative-destruction happens in the sense that $\mathrm{R} \& \mathrm{D}$ may result in the discovery by an Entrepreneur of a new leading-edge technology which forces the incumbent firm to exit the market. At each date, production by the successful Entrepreneur is a two stage process: there is a "quality" stage where a set of strategic actions must be undertaken by an Agent hired by the Entrepreneur in order to adapt the leading-edge technology to an exogenously changing market environment; then there is a "quantity" stage where workers are hired to produce with the technology. During the quality stage, the Entrepreneur must transmit to the Agent some information about the set of correct strategic actions. Actions being costly to the Agent, there is room for moral-hazard and hold-up: indeed we assume that due to imperfect verifiability by a third party the Agent can always choose a wrong action at a lower cost. This moral hazard problem can be solved by the Entrepreneur through two different margins: the KM policy and the organizational structure.

We consider two types of information transmission policies (ie. KM policies). The Entrepreneur can have a "face-to-face" interaction with the Agent where information on actions remains soft and there is only transmission of the bit of information relevant for the current period. Alternatively, the Entrepreneur can undertake codification where the Agent receives a blueprint (or plan of actions) specifying the set of relevant actions. In this way, soft information is transformed into hard information. Codification allows the writing of formal contracts that solve the moral-hazard problem. At the same time though, codification has a cost in term of informational spillover as we assume that the share of hard information is immediately available to other $\mathrm{R} \& \mathrm{D}$ competitors who may use it to leapfrog the leading edge firm. Hence, in spite of the moral hazard problem, the entrepreneur may still choose to keep information soft in order to reduce competitive pressures. The Entrepreneur can mix the two policies by codifying only a share of the actions while the residual share of information remains soft and is transmitted through face-to-face interaction.

We consider two different organizational structures. The first one corresponds to "in-house" relational labor contracts involving a repeated relationship between the Entrepreneur and the Agent. In such a situation, the moral-hazard problem is solved through the delivery of an ex-post informal bonus that is paid if the Agent has undertaken the set of correct actions. The second one corresponds to joint-ownership of production by the Entrepreneur and the Agent. The Agent internalizes now the surplus enhancing effect of choosing the correct actions and this therefore solves the moral hazard problem.

We analyze how the optimal KM policy of firms (ie. the share of soft information) interacts with their optimal organizational structure (in-house versus joint-ownership) and their competitive environment. Our first partial-equilibrium result is that joint-ownership is compatible with more informational 
softness than in-house production. The reason is that under in-house relational contracts and large informational softness, the moral-hazard problem is so severe than the Entrepreneur may be tempted to renege ex-post on the (large) bonus. To the contrary, joint-ownership is an ex-ante commitment and can thus credibly sustain larger informational softness. As a consequence joint-ownership limits codification and informational spillover toward competitors. This makes joint-ownership optimal when technological competition is intense. By contrast, in-house production with codification is preferred by the Entrepreneur when intensity of technological competition is low. In that case information spillover are not too harmful, codification dampens the moral hazard problem and this reduces the share of the surplus that the Entrepreneur must transfer to the Agent.

Closing the model in general equilibrium allows us to derive implications at the macroeconomic level. We provide two interesting comparative statics. First, we highlight the existence of a Bell-shaped effect of technological competition on codification. We believe this result to be roughly consistent with some patterns of long run development of various developed economies: the switch from craftsmanship to mass-production and then to the "knowledge-based" economy (see Mokyr, 2002, for a discussion). In particular, our analysis suggests that the increased diffusion of Information Technologies may paradoxically induce an increased reliance on soft information and tacit knowledge; this being also associated with major shifts in terms of work organizational structures at the corporate level. This view is consistent with some stylized facts uncovered by Autor, Murnane and Levy (2003).

Second, our theoretical analysis relates to the nature of scale effects involved in the growth process, namely the fact that growth rates are positively related to the stock of resources available for innovation and $R \& D$. The debate in the growth literature focuses on the strength of those scale effects: While evidence based on historical trends in the very long run is compatible with the existence of strong scale effects, empirical studies of growth patterns based on post WWII evidence suggest that scale effects are in fact quite weak (see Jones, 2005, for a discussion). By endogenizing information flows (soft versus hard) and the associated structure of spillover in the economy, our approach provides an explanation for the changing nature of scale effects during the growth process.

The paper is then organized as follows. Section 2 discusses the related literature and how we contribute to it. Section 3 then describes some stylized facts from the Knowledge Management literature that our model will incorporate. Section 4 presents formally the model. In Section 5, the model is solved and the main results are discussed. Our comparative statics are then performed in section 6 . Finally, section 7 concludes. Proofs and formal assumptions are relegated to the appendix.

\section{Related literature}

This paper is related to several strands of literature. In our framework, the degree of contractual incompleteness is endogenous. This is related to Battigalli and Maggi (2002) who argue that the limit 
to contractual completeness comes from the direct cost of writing contracts. Here we rather emphasize the importance of information spillover and outside competition in affecting incompleteness. Our model endogenizes the mix between formal aspects of organization (understood as job description, formal contracts, etc.) and the informal aspects (as relational contracts, reputation, and non contractual dimensions, etc.). This mix is a crucial feature of organizations; it has long been emphasized by the sociological literature and more recently addressed by the economic literature (see Baker, Gibbons and Murphy 2002). Our paper contributes to this line of research by highlighting that this mix is endogenous and shaped by the policy of knowledge codification at the firm level.

This paper also contributes to a recent emerging literature analyzing the links between the internal organization of the firm and macroeconomic growth. Thesmar and Thoenig (2000) for instance consider a model in which firms implement production projects through two alternative organizational structures. They can choose between a "mechanistic" organization that provides high productivity at the expense of a sunk cost and an "organistic" organization that provides low productivity without sunk costs. Larger growth through creative destruction reduces the expected lifetime of projects and therefore reduces the firms' incentives to adopt the "mechanistic" organizations. In this way, the macroeconomic environment impinges on the organizational choices of firms. On the other hand, firms' organizational choices feed back into the growth rate of the economy as changes in organizational structures affect the firms' profitability and research activity.

Martimort and Verdier (2004) investigate the possibility of internal self-enforcing collusive agreements between workers within the firm and how it interacts with the macroeconomy. Typically, long lived projects and their associated repeated interactions allow managers to sustain collusive outcomes which bring inefficiencies at the firm level. Larger innovation rates increase the turnover of projects and undermine this capacity of self enforced collusion. This in turn increases the internal efficiency of the firms and stimulates further incentives for research and innovations.

Closest to our work, François and Roberts (2003) analyze the contracting problem between the owner of an innovation (the firm) and a manager that is supposed to implement the project. In an incomplete contracting setting, they also emphasize two types of self enforcing contracts that can solve the hold-up problem between the innovator and the manager. In the first case ("the contractor" case), the moral hazard problem resides in the manager that needs to provide the right effort after the innovator committed payments. In the other case ("the internal labor market"), the firm is subject to moral hazard in the payment after the manager already provided his effort. Growth and turnover makes it harder for the firm to sustain the "internal labor market" self enforcing solution. This shifts the optimal organizational structure towards the "contractor" solution, moving the division of the surplus in favor of the manager. This in turn affects negatively the incentives for innovation and macroeconomic growth.

A distinctive element of our work is the idea that firms can control the degree of information softness present in their organizational structure. This feature has two consequences. First, with 
knowledge codification, a firm can increase the level of explicit contracting with its workers within its organization. Second, the resulting degree of information softness affects the level of knowledge external spillover that competitors enjoy, impacting therefore the competitive pressures that this firm will face. The nature of endogenous knowledge spillover generates then a feedback effect from the microstructure of the firm to macroeconomic growth.

Beyond internal relational labor contracts, we also allow firms to have the possibility to have joint ownership with the manager and to rely on ex-post bilateral bargaining. As in Francois and Roberts (2003), when growth increases, this strategy becomes more likely. The mechanism through which this occurs however is different. In Francois and Roberts (2003), as growth increases, faster turnover makes it harder for the firm to sustain an "internal labor market" self enforcing solution. At some point, firms cannot credibly commit to paying employees in the future for effort exerted today and the only possibility then is to shift to the "contractor" solution and leave to the manager an ex-ante "efficiency" wage. In the present paper, ownership leaves ex-post rents to the manager and solves his moral hazard problem irrespective of the degree of information softness. Given this, the firm is able to implement a full degree of internal information softness. This in turn reduces knowledge spillover and the probability to be leapfrogged by a competitor, increasing thereby the expected lifetime of the firm. This option is all the more valuable the larger the growth rate of the economy. Hence, in addition to affect the division of the surplus between the firm and the manager, a change of organizational structure in our model also affects the nature of informational flows in the economy, providing therefore a further channel of impact on the incentives for innovation and thereby macroeconomic growth.

Finally, at a more general level, a significant amount of work emphasizes the importance of technological spillover in models of endogenous growth, development, international trade and economic geography. It is well known that results emanating from these models are drastically affected by the specification of spillover (local vs global). While aware that the size and scope of spillover are linked to the existence of soft information (see Krugman 1991) most of these theories take the nature of spillover as exogenously given. Our model is a first step towards endogenizing this aspects by providing micro-foundations of some information transmission processes.

\section{$3 \quad$ Stylized Facts on knowledge management}

Before getting into the formal analysis, we outline in this section some stylized facts from the Knowledge Management and related Business literature that we think are relevant for our theoretical framework. 


\subsection{The tacit component of Knowledge}

The standard approach in the economics of information is to consider knowledge as sharing public good characteristics such as non rivalry and costless transferability (see Arrow 1962). Still, there is a well established tradition among practitioners of the firm insisting on the fact that knowledge is partially tacit and only partially transferable (Davenport, Konoka, Von Hippel 1994, Nickerson and Zender 2002). In the economic literature, Polanyi (1958) is the first to establish the existence of a component of knowledge which is essentially tacit, contextual and not easily expressible to someone else. Nelson and Winter (1982) also emphasizes the importance of knowledge tacitness and information softness in skill-intensive activities.

The concept of tacit knowledge has also been popularized by the school of Sociology of Scientific Knowledge. Studies by Collins (1974) for the case of the construction of the TEA laser or by McKenzie and Spinardi (1995) for the design and construction of nuclear weapons in the US during WWII, both emphasize the idea that some kind of knowledge deployed in scientific inquiry (ie. reading and interpreting the data, design of experimental instruments,...) is not transmitted among researchers through explicit and codified statements.

\subsection{KM policies are a mix between face-to-face interactions and codified proce- dures}

One important dimension of KM policies emphasized by the literature (Hansen, Norhia and Tierney 1999; Quintas 2003) is the fact that KM policies are basically a mix between two types of practices commonly used by firms: so called "personalization" where knowledge remains in its tacit form and is shared through face-to-face interaction and "codification" where information is hard, proceduralized and available to anyone in the company. Quoting Foray and Gault (2003): " [In] Personnalization, knowledge remains in its tacit form and is closely bound to the person who developed it; it is shared primarily through person-to-person contact. To make this strategy work, companies invest heavily in networks of person (mobility, culture of bilateral interaction)...". On the other hand codification involves the setup of written documents and regularly updated databases where training manuals, good work practices and more generally so-called "organizational memory" are stored. As such, codification is more efficient when supported by the intensive use of ICT.

\subsection{Codification of knowledge is a strategic choice variable}

Case studies support the view that codification of knowledge is not only driven by technological feasibility but results also from a strategic choice at the firm level. Hansen et al., (1999) report differences of KM strategies within the consulting industry: Ernst \& Young and Andersen Consulting have developed firm-wide IT systems for document sharing and best practices codification while, on the contrary, 
McKinsey consultants and Bain\&Company rely on networking, face-to-face interactions and an informal culture of experts. Baumard (1999) discusses how, the Australian airline Qantas tried to introduce a new computer-based policy favoring documents, manuals and computerized information and faced opposition of pilots preferring non formal circulation of knowledge. The OECD (2003) systematic survey on KM practices across various countries reports that most firms undertaking KM strategies and codification procedures, do this with the specific goal of information sharing and information capturing and that, even within an industry (ie. for the same types of products) the KM strategy may vary according to the external business strategy that the firm seeks to develop.

\subsection{Information softness reduces technological spillover across firms}

The innovation literature recognizes the importance of the distinction between tacit and codified knowledge in understanding the role of technological spillover (Kogut and Zander 1996, Teece 2005, Audretsch, Keilbach and Lehman, 2006). More specifically, the idea that information softness tends to reduce external technological spillover is consistent with evidence gathered in the empirical literature on technology spillover and diffusion. An important stylized fact from that literature is the fact that knowledge spillover are spatially localized and that the scope of this spatial effect is negatively linked to the existence of soft information (Audretsch and Feldman 1996, Keller 2002, Feldman and Lichtenberg 1997). Indeed as pointed by Jaffre (2002) geographical location is important in capturing the benefits of spillover only to the extent that the transfer of information is obtained through informal and localized interactions, as is typically the case for soft information and tacit knowledge items.

Conversely, codified knowledge is more likely to lead to cross-firm informational leakages. An interesting example of this is related to the case of "industrial espionage". Simm and Ferdinand (2006) discuss various case studies suggesting that informational leakages of that sort are greatly facilitated by the existence of encoded procedures and information blueprints. They report in particular the case of a bidding competition between Boeing and Lookheed worth $2 \$$ billion contract for a US Air Force contract for rocket-launchers in 1988. In order to get access to confidential information on its competitor, Boeing hired a former employee from Lookheed who brought with him proprietary documents of about 8,800 pages revealing secret information on Lookheed procedures. In a subsequent investigation, the US Air Force also found that Boeing had acquired other 25,000 Lockheed documents suggesting that the initial case was not an isolated incident and that information transfer from Lookheed to Boeing had been facilitated by Lookheed's codification of knowledge into these documents and blueprints (Swartz 2003).

Interestingly, the development of Information Technologies (IT) has also been reported to promote the potential for informational leakage of codified knowledge. The Computer and Security literature emphasizes how the Internet and associated technologies have already revolutionized the collection and analysis of competitive information. Open source information provides a wealth of knowledge 
for industrial competitors because those sources take a variety of forms including newspaper articles, corporate Annual Reports, patent filings, court papers, and marketing information. By reviewing these legal open sources, competitors can determine a significant amount of information about a company and their products. From a non legal point of view, Boni and Kovacich (2000) in their book on "Netspionage", discuss how the enhanced use of IT and communication networking tools increased the vulnerability of the firm's codified information assets to spying attacks from "hackers," "cyberpunks," and even intelligence agencies.

\subsection{KM policies come as a trade-off between internal organizational constraints and external competitive pressures}

The management literature emphasizes the view that knowledge management has to balance between internal organization constraints and external competition pressures (see Nickerson and Todd, 2002, and Sanchez and Heene, 1998). As a matter of fact, the two-sided nature of soft information, both as a source of contract incompleteness inside a relationship and as a source of protection against external technological competition, is clearly illustrated by Sanchez and Heene (1998) in their literature survey on "Managing Articulated Knowledge in competence-based competition". On the one hand they acknowledge that : Much current discussion of knowledge in competence-based competition advances the proposition that a firm's "tacit knowledge" is more likely to be a source of competitive advantage than the firms' articulated or "non-tacit" knowledge [...] The difficulty of observing and acquiring "tacit knowledge" limits its diffusion beyond the firm [...]. This view is consistent with the idea that information softness by reducing external informational spillover to competitors tends to provides benefits to the firm. At the same time though, Sanchez and Heene (1998) also emphasize that: Relying on "tacit knowledge" as a source of strategic advantage limits the ability of a firm to leverage its knowledge [...] the potential for leveraging is much greater when that knowledge can be articulated, codified", suggesting therefore some internal efficiency costs to the firm.

\subsection{There is a recent decline in knowledge codification associated with IT diffusion}

A recent paper by Autor, Murnane and Levy (2003) provides direct evidence that there has been a rise in non procedural activities since the 70s. Using samples of the CPS matched with representative data on job tasks requirements from the Dictionnary of Occupational Titles (DOT), they show that by 1998, non routine analytic task input averaged 6.8 centiles above its 1970 level and nonroutine interactive input averaged 11.5 centiles above its 1970 level. The main point of their paper is that this rise is pervasive at all educational levels and is accounted by the rapid diffusion of computers at

the industry level. While Autor and al.'s interpretation hinges on the fact that computers directly substitute to procedural tasks at the firm level, this evidence is also consistent with the idea that the spread of IT, by triggering competition and imitation at the industry level, induces firms to relax 
their degree of knowledge codification and increase agents' empowerment as a defensive competitive strategy. As we will see this will be consistent with one of the main implications of the model.

\section{The Setup}

We consider a discrete time quality ladder growth model à la Grossman and Helpman (1991)

\subsection{Goods and factors of production}

In period $s$, there is a numeraire competitive final good $Y_{s}$ using a continuum of intermediate goods $x_{i s}$ on the interval $[0,1]$ under a Cobb-Douglas technology $\log Y_{s}=\int_{0}^{1} \log x_{i s} d i$. As usual, the per-period demand for intermediate good $i$ with price $p_{i s}$ is given by:

$$
x_{i s}=\frac{Y_{s}}{p_{i s}}
$$

There are two types of production factors. First, there are $H+1$ entrepreneurs endowed with human capital and are involved in innovation competition and firm management. Second, there is unskilled labor in quantity $L$ that is also freely mobile across sectors and used in project implementation and production of the intermediate goods.

\subsection{Preferences}

The representative consumer is endowed with the following intertemporal separable utility function: $U_{t}=\sum_{s=t}^{+\infty}(1+\beta)^{-(s-t)}\left[Y_{s}-e_{s}\right]$ where $Y_{s}$ corresponds to date $s$ consumption and $e_{s}$ to the nominal cost of effort. We assume ${ }^{3}$ that the shadow price of effort increases at the growth rate of this economy: $e_{s+1}=\left(1+g_{s}\right) e_{s}$. There is a perfect credit market. Therefore, given the intertemporal linearity structure of preferences, the equilibrium real interest rate $r$ is such that $r=\beta$, the discount factor.

\subsection{Technological Change and competition}

In each industry $i$, at each period $s$ there is an endogenous amount $H_{i s}+1$ of entrepreneurs who are involved in technological competition in that sector. After discovering a leading-edge project, an entrepreneur must implement the project by creating a firm and hiring workers. When ruling a firm, that entrepreneur cannot undertake at the same time some research effort. Hence research will be done by the $H_{i s}$ entrepreneurs who are not currently managing a firm.

\footnotetext{
${ }^{3}$ Given that effort enters additively into the utility function of the representative consumer, this assumption allows the existence of a constant steady state growth equilibrium path. It could be justified by saying that effort could alternatively be allocated to home production, whose productivity grows at the same rate as the rest of the economy because of exogenous spillovers effects from market to home production.
} 
We assume that in each period, each of the innovating entrepreneurs has a Poisson rate of success that depends on whether he benefits or not from informational spillover from the leading-edge firm in his sector. More specifically, we assume that a given entrepreneur has a probability $\phi \in] 0,1[$ to receive such informational spillover. In such a case, his success rate of innovation is $\left(1+\varepsilon_{i}\right) \theta_{0}$ where $\varepsilon_{i}$ captures the endogenous degree of knowledge spillover within industry $i$. We discuss below how the spillover parameter $\varepsilon_{i}$ can be partially manipulated by the leading edge firm in order to reduce the probability of being destroyed. With the residual probability $1-\phi$, the entrepreneur just enjoys a benchmark success rate $\theta_{0}$. We see that $\phi$ therefore captures the easiness with which firms can learn crucial information on their competitors through reverse-engineering, "competitive intelligence" strategies or "industrial espionage" as described in section 3. An increase in $\phi$ could capture the rise of communication and information technologies in the economy. ${ }^{4}$ From this, it follows that the per period rate of competitive pressure $\theta_{i s}$, which stands for the probability for a new project to be discovered in an industry $i$, is simply given by

$$
\theta_{i s}=(1-\phi) \theta_{0} H_{i s}+\phi\left(1+\varepsilon_{i}\right) \theta_{0} H_{i s}=\theta_{0}\left(1+\phi \varepsilon_{i}\right) H_{i s}
$$

Entrepreneurs can freely choose the sector in which they wish to undertake research. Active innovation in all sectors $i \in[0,1]$ implies therefore the following arbitrage condition :

$$
\theta_{0}\left[(1-\phi)+\left(1+\varepsilon_{i}\right) \phi\right] V_{i s}=\theta_{0}\left[(1-\phi)+\left(1+\varepsilon_{j}\right) \phi\right] V_{j s} \text { for all }(i, j) \in[0,1]
$$

where $V_{i s}$ is the firm value to be at the leading edge in sector $i$ starting at time $s$ (to be computed later). Condition (3) simply says that the expected value of innovation should be the same across sectors.

\subsection{Production and Hold-up}

Within each industry $i$, each new project enhances the productivity of the previous leading-edge project by a parameter $\delta$ with $0<\log \delta<1$. Then, within each period $s$, the leading edge firm produces according to a two-stage process. Firstly, in the "quality" stage, a set of strategic tasks must be done in order to adapt the production process to changing environmental conditions. Secondly, in the "quantity" stage, an amount $l$ of workers are hired in order to produce with the leading-edge technology:

$$
y_{i s}=\delta^{n_{i s}} l
$$

where $n_{i s}$ is the quality index of the leading edge-firm in period $s$ such that $\delta^{n_{i s}}$ corresponds to the productivity of this firm. Firm's unit cost of production is equal to $c_{i s}=\bar{w}_{s} / \delta^{n_{i s}}$ where $\bar{w}_{s}$ is the competitive wage prevailing on the labor market.

\footnotetext{
${ }^{4}$ As already mentionned, Boni and Kovacich (2000) suggest that this enhanced use of IT and communication networking tools would increase the possibility of "netspionage" and the vulnerability of the firm's codified information assets that can be accessed by competitors through these communication tools.
} 
Consider first the "quantity" stage. Due to limit-pricing in Bertrand competition between the new project and the previous one, the price $p_{i s}$ charged by the new firm is equal to $\delta c_{i s}$ where $c_{i s}$ is the new firm's unit cost of production at time $s$. Using (1), this means that each project generates a cash-flow equal to :

$$
\pi_{i s}=\left(1-\delta^{-1}\right) \cdot Y_{s}
$$

Consider now the "quality" stage. It needs to be undertaken by an Agent, hired on the unskilled labor market, whose job consists in implementing a set of strategic tasks $j \in[0,1]$ : All tasks must be correctly implemented otherwise production does not take place. For each task $j$, correct implementation requires that the Agent undertakes ${ }^{5}$ a time-dependent "correct" action $a_{j s}^{*}$ at a cost $e_{s}$.

In the "quality" stage, there is some room for opportunism because we assume that: (1) the Agent is always able to undertake, at zero cost, a wrong action $a_{j}$; $(2)$ the quality (ie. "correct" or "wrong") and the costs (ie. $e_{s}$ or 0 ) of actions $a_{j}$ are not verifiable by an outside party ${ }^{6}$. Consequently, in absence of a blueprint or a contract describing ex-ante the correct actions $a_{j s}^{*}$ for each date $s$, there is an hold-up problem. If the agent undertakes the correct action $a_{j s}^{*}$ at cost $e_{s}$, the firm has an incentive to deny the quality of her action in order not to pay her ex-post. Anticipating this, the agent has incentives to undertake a wrong action at zero cost.

\subsection{The role of codification: from soft to hard information.}

Strategic information of the leading-edge firm in a given sector $i$ corresponds to $\left\{a_{j s}^{*}\right\}$, the set of correct actions (or "best practices" as usually denoted in the management literature). Initially this set of information is appropriated by the entrepreneur only (because she is the successful innovator). The purpose of the KM policy is to share this piece of information with the Agent who needs it to implement correctly the "quality" stage.

As emphasized in the existing empirical literature, we consider two types of KM policies: (1) "faceto-face" interaction: for a given task $j$, information remains soft and at each date $s$, the entrepreneur gives to the Agent only the bit of soft information $a_{j s}^{*}$. There is no direct communication cost. (2) codification: for a given task $j$, at the beginning of the relationship, the entrepreneur gives to the Agent a blueprint (or a code of procedures) specifying the correct actions for all periods and contingencies $\left\{a_{j s}^{*}\right\}_{\forall s \in(1,2, \ldots)}$. Hence soft information is made hard. There is no direct cost of codification. The KM policy implemented by the entrepreneur mixes both strategies. For the leading-edge firm in a given

\footnotetext{
${ }^{5}$ We assume that the set of possible actions is so wide that an Agent ignoring ex-ante $a_{j s}^{*}$ has no chance of implementing correctly task $j$. Moreover $a_{j s}^{*}$ evolves in an unpredictable way such that learning by the Agent is not possible.

${ }^{6}$ Contracts could be made contingent on the quality of the product or the amount of sales. The hold up problem would then disappear. To restore the hold up problem, we would need then to assume that there are $n$ managers per firm and that quality is the result of the joint effort of the $n$ managers. Hence the impact of a particular manager on total quality could not be inferred.
} 
sector $i$, a share $\gamma_{i}$ of the continuum [0,1] of tasks is kept under soft information and is transmitted through "face-to-face" interaction, while a share $\left(1-\gamma_{i}\right)$ is codified. The choice of $\gamma_{i}$ is made at the beginning of the discovery of the leading-edge technology and is irreversible.

Codification benefits to internal efficiency. Indeed, by transforming soft information into hard information (ie. the blueprint), codification allows to write down a formal contract describing the set of correct actions which have to be done by the Agent; this consequently solves the hold-up problem for the $\left(1-\gamma_{i}\right)$ codified tasks only.

Codification however has a cost in term of information leakage. As suggested by the KM literature, codified information assets are more vulnerable to external diffusion to competitors, especially so with the increased use of IT, Internet and communication technologies. First, codified knowledge can be more easily attacked from the exterior by competitors, hackers and industrial spies. Second, there is a basic increased vulnerability in the transformation problem from soft (non verifiable) information to hard (verifiable) information. Information leakage cannot be perfectly contracted upon, in the sense that information leakage is neither completely observable nor itself verifiable. Indeed, the third party (ie. the lawyer or consultant) who writes down and certifies the contract cannot fully commit not to reveal to an outside competitor the codified information enclosed in the contract whether through legal or illegal means. Also, the Agent may be able to transmit a piece of hard information to an outside competitor without being convicted ${ }^{7}$. The Agent could finally alternatively use the knowledge himself to compete successfully with the leading-edge firm. In a context with imperfect credit markets, this agent might not be able to fully fund the project himself. In such a case, he will get better credit conditions if he can convince potential creditors that his project is viable and competitive. This is of course more likely when he can supply hard information and codified knowledge emanating from the leading-edge firm's project.

To sum up, these different channels are likely to increase the probability of diffusion of hard and codified information compared to soft information. We capture this by assuming that the industrylevel knowledge spillover $\varepsilon_{i}$ depend positively on the share $\left(1-\gamma_{i}\right)$ of hard information and that this immediately and costlessly spreads with some probability $\phi$ to the competitors' population (in mass $\left.H_{i}\right)$. Formally, we assume that the spillover $\varepsilon_{i}$ takes the simple form $\varepsilon_{i}=\lambda\left(1-\gamma_{i}\right)$ with $\lambda^{\prime}()>$.0 and $\lambda^{\prime \prime}()<$.0 . Together with $(2)$ this leads to the following competitive pressure rate:

$$
\theta_{i s}\left(\gamma_{i}\right)=\Psi\left(\gamma_{i}\right) H_{i s}
$$

with $\Psi \equiv \theta_{0}+\theta_{0} \phi \lambda\left(1-\gamma_{i}\right)$ such that $\Psi^{\prime}<0$ and $\Psi^{\prime \prime}<0$.

We see that the degree of information softness $\gamma_{i}$ stands either for the degree of contractual incompleteness and the size of spillover. This dual aspect comes basically from the fact that codification (ie. switching from soft to hard information) enables the design of more precise contracts but simultaneously

\footnotetext{
${ }^{7}$ The case previously discussed by Simm and Ferdinand (2006) of about 25000 Lockheeds confidential documents transmitted to Boeing is a suggestive example of the importance of such possibility.
} 
promotes informational leakage.

The trade-off faced by the firm is then pretty clear. Despite the underlying hold-up problem the firm may still choose to keep part of information soft (ie. $\left.\gamma_{i}>0\right)$ to reduce information spillover and competitive pressures. In that case, the firm must use an alternative instrument to mitigate the hold-up problem. Relational contracts (ie. repeated interactions between the firm and the Agent) or the ownership structure (as studied by the incomplete contracting literature, Grossman and Hart 1986) are two possible alternatives.

\subsection{Steady-state}

We focus on steady-state symmetric growth path equilibria across sectors such that ${ }^{8} \forall i, j, V_{i s}=V_{j s}$, $H_{i s}=H_{j s}=H, \gamma_{i}=\gamma_{j}=\gamma, \theta_{i s}=\theta_{j s}=\theta(\gamma)=\Psi(\gamma) H$. Moreover all the following variables grow at the same pace $g$ :

$$
Y_{s}=(1+g)^{s} Y_{0}, e_{s}=(1+g)^{s} e, \bar{w}_{s}=(1+g)^{s} \bar{w}, \text { and } V_{i s}=V_{j s}=V(1+g)^{s}
$$

where $g$ is the stationary growth rate prevailing in the economy and equal to ${ }^{9}$ :

$$
g=\theta(\gamma) \cdot \log \delta
$$

where $\theta($.$) is given by equation (6). As \gamma \in(0,1)$, this equation shows that the equilibrium value of $g$ can take value only within the range $[0, \bar{g}]$ where $\bar{g}=\theta(0) \cdot \log \delta$. Finally, we assume for the sake of computational simplicity that the growth rate $g$, the interest rate $r$ and the creative destruction rate $\theta$ are small with respect to 1 . This amounts to saying that the length of periods is short enough so that our discrete model behaves almost as a standard continuous time models of growth. ${ }^{10}$

\section{The basic results}

This section studies the two instruments used by the firm for solving the hold up problem, namely relational contracts and ownership structure. We provide here only the sketch of the argument: all technical details are given in the appendix.

\footnotetext{
${ }^{8}$ This comes immediately from the human capital resource constraint $\int_{0}^{1} H_{i s} d i=H$.

${ }^{9}$ The steady-state growth rate $g$ is computed as in Grossman and Helpman (1991) (see chapter 4 for details). Denoting $n_{i s}$ the degree of quality prevailing at date $s$ in industry $i$. From limit pricing we get that the price in each industry is equal to $p_{i s}=\bar{w}_{s} / \delta^{n_{i s}-1}$ where $\bar{w}_{s}$ is the competitive wage. Remind that the price index, $P_{s}$, is equal to: $\log \left(P_{s}\right)=$ $\int_{0}^{1} \log \left(p_{i s}\right) \cdot d i$. As $Y$ is chosen as a numéraire, we get that $\log \bar{w}_{s}=\int_{0}^{1} \log \left(\delta^{n_{i s}-1}\right) \cdot d i$ and the stationary rate of growth is given by $g=\theta \log \delta$.

${ }^{10}$ As the reader will soon figure out, the focus on discrete time is motivated by our desire to model the relationships within the firm as a repeated game, the analysis of which is much easier in discrete time.
} 


\subsection{In-house relational contracts}

Consider now relational employment contracts inside the organization. At the beginning of the relationship the firm designs a contract. This contract codifies a share $(1-\gamma)$ of the tasks and specifies a wage schedule $\left\{w_{s}\right\}$ which has to be paid to the agent whenever theses tasks are correctly done. Hence the contractual payment $\left\{w_{s}\right\}$ is contingent to only a share of the total set of tasks. With regards to the non codified part $\gamma$ of know-how, the agent is "free" to undertake them (at a total cost $\gamma e_{s}$ ) as this part of the job is not described in the contract.

The underlying opportunism problem can be solved through relational contracts. The agent is willing to undertake the non codified actions (despite the threat of hold-up) if she expects to get a compensation for her non contractual effort. This compensation takes the form of a non contractual wage $\omega_{s}$ (a bonus) that the firm gives ex-post. As a consequence, an employment relational contract implicitly specifies two things. First, the agent must undertake at each date $s$ the correct actions on the full set of tasks $[0,1]$. Second, the agent receives in exchange a sequence of wage payments $\left(w_{s}\right.$, $\omega_{s}$ ) where $w_{s}$ is the formal component paid when the agent proceeds with the right verifiable actions (on the share $(1-\gamma)$ of codified tasks), and $\omega_{s}$ is a promised non contractual wage paid when the agent executes the right job on the $\gamma$ remaining non codified tasks. That contract needs to be self enforcing for the two parties. Therefore, it should satisfy a) incentive compatibility constraints, both for the agent and the firm, b) the agent's individual rationality constraint.

The agent's incentive constraint: Focusing on detrended stationary contracts along a stationary growth path, it can be shown that for small values of $r, \theta$ and $g$, the incentive compatibility constraint of an agent writes as:

$$
\gamma e \leq \omega+\frac{w+\omega-e-\bar{w}}{r+\theta-g}
$$

This has a straightforward interpretation. The one period gain from cheating ${ }^{11}$ (saving the effort cost $\gamma e$ on non verifiable tasks) should be less that the value of not cheating. The latter is the sum of the bonus $\omega$ received at the end of the period and the expected discounted gains of the cooperative employment relationship in the future. Condition [MIC] clearly shows that any share $\gamma$ of information softness can be sustained from the agent's point of view as soon as the bonus $\omega$ is sufficiently large. Unfortunately, the firm will tend to renege on large values of $\omega$ and this instrument is difficult to enforce from the firm's point of view (see below).

The firm's incentive constraint: Similarly the firm's incentive constraint can be written as:

$$
\omega \leq \frac{\pi-w-\omega}{r+\theta-g}
$$

The one period gain from cheating ${ }^{12}$ on the agent and not paying the bonus $\omega$, has to be less than

\footnotetext{
${ }^{11}$ After cheating, the agent is fired by the firm and goes back to the labor market with a bad reputation. This reputation prevents her to be hired by other firms as a manager and thus constraints her to earn the reservation wage $\bar{w}$ (see appendix for all the details).

${ }^{12}$ After cheating on the agent, the firm gets a bad reputation and no agent will accept to work for the firm as a manager. The firm is thus unable to produce anymore and gets 0 cash-flow (see appendix for all the details).
} 
the expected discounted value of the cooperative relationship to the firm (ie. the RHS). This equation clearly illustrates the trade-off in term of incentives from the firm's point of view. The larger is the ex-post non-contractual wage $\omega$, the more the firm wants to renege. The larger is the net surplus of the relationship the more the firm wants to cooperate.

The agent's participation constraint: The per period value of employment $w+\omega-e$ must be equal to, or larger than, the opportunity cost of working as a production worker $\bar{w}$. The appendix shows that the optimal contract is such that the participation constraint is always binding:

$$
w+\omega-e=\bar{w}
$$

For a given stationary growth rate $g \in(0, \bar{g})$, the optimal problem of the firm is to maximizes its expected discounted value with respect to information softness $\gamma$ under (PC)-(MIC)-(FIC), which in detrented value is equal to:

$$
V=\underset{\gamma}{\operatorname{Max}} \frac{\pi-e-\bar{w}}{r+\theta(\gamma)-g}
$$

Given that the rate of creative destruction $\theta(\gamma)$ is decreasing in $\gamma$, the firm wants to implement the largest possible value of $\gamma$. Plunging (PC) in conditions (MIC) and (FIC), this means that the optimal $\gamma$ and $\omega$ are given by the largest value of $\gamma$ such that: $\gamma e \leq \omega \leq \frac{\pi-e-\bar{w}}{r+\theta-g}$. This gives:

Result 1: Under in-house relational contracts, the optimal contract is such that: a) the contractual wage compensates the agent for the codified share of know-how only, $w=(1-\gamma) e+\bar{w}$; $b)$ the non contractual wage compensates for the non verifiable share of know-how, $\omega=\gamma e$. The optimal degree of information softness $\gamma(g)$ is below 1 , is increasing with the growth rate $g$ and is such that:

$$
\gamma e=\frac{\pi-e-\bar{w}}{r+\theta(\gamma)-g}
$$

The intuition is the following. Given that the rate of creative destruction $\theta(\gamma)$ is decreasing in the degree information softness $\gamma$, the firm would like to implement the largest possible value of $\gamma$ sustainable through a relational contract $(w, \omega)$. The sustainability of $\gamma$ is however restricted by the fact that the non contractual bonus $\omega$ has a limited impact: A large $\omega$ always provides correct incentives to the agent (see MIC), but not to the firm who may have interest to renege on $\omega$ instead of rewarding the agent. Given the absence of a commitment device from the firm's point of view, the latter has to choose a value of $\gamma$ strictly less than 1 (codification of information) to mitigate the internal hold up problem.

An increase in the growth rate $g$ tends to increase the degree of information softness $\gamma$. Intuitively, the larger the growth rate $g$, the more valuable the future cash-flows and wages. It is then important both for the firm and the agent not to renege now in order to enjoy the gains from future cooperation. Cooperation becomes easier for both sides and, consequently a larger degree of softness is sustainable. We call capitalization effect this positive impact of growth on information softness. 
Note finally that in this type of employment relationship, the firm's present value writes as:

$$
V^{i n}(g)=\frac{\pi-e-\bar{w}}{r+\theta(\gamma)-g}
$$

\subsection{Joint ownership and Empowerment}

So far, the problem of a two-sided hold-up inside the firm was solved by the use of relational contracts and reputation based incentives. An alternative is to empower the agent by making a transfer of ownership in his favor. In that case, the firm does not rely on repeated interactions and relational contracts but on static ex-post bargaining power which is transferred to the agent, as for instance studied in the incomplete contracting literature ${ }^{13}$. Transfer of ownership affects the status quo points of the two parties compared to in-house employment contracts and therefore may have strong implications on the ex ante incentives.

As before, at the beginning of the relationship the firm decides its level of informational softness $\gamma$, taking as given the rest of the economy. Under Joint Participation, the agent owns his production such that $p$ is the price at which the agent will sell production to the firm. This price will be negotiated ex post between the two parties at the end of the spot relationship. We assume also that the agent has a limited liability constraint ${ }^{14}$. Finally we assume that joint-ownership does not increase communication costs between the firm and the agent. ${ }^{15}$ As already said, for the firm the benefit of transferring ownership to the worker comes from the fact that the hold up problem is partially solved in a one-shot interaction. Therefore, the firm is able to sustain a higher level of information softness and can protect better its incumbent position against technological competition. The cost of joint ownership is the fact that the firm now looses some rents (whereas in the in-house relationship it was capturing the whole surplus).

Consider now the price $p$ at which the agent sells his production to the firm. This price is fixed after a bilateral bargaining stage which maximizes the joint surplus $\pi$. Outside options of both agents are zero and we immediately get that: $p=\frac{\pi}{2}$.

The agent receives $p$ only when the overall quality is achieved. Given that the surplus of the relationship is assumed to be large enough, ie. $\pi / 2-e>\bar{w}$, (see assumption $A_{3}$ in appendix), the agent always undertakes the full degree of effort whatever the degree of softness of information. As a consequence, the firm is able to sustain, under joint ownership, an extreme level of softness $\gamma=1$ in order to reduce information leakage. From the firm's point of view, the surplus is equal to $\pi / 2$ at

\footnotetext{
${ }^{13}$ Here we consider only the case of spot outsourcing contracts in which the firm decides to transmit ownership to the agent of tasks the latter is supposed to produce (the firm keeps ownership on the remaining tasks). See Baker, Gibbons and Murphy (2002) for a discussion on relational outsourcing contracts.

${ }^{14}$ In our present setting, the assumption of limited liability implies that there could not be an ex-ante license fee, $W$, that the agent pays to the firm in order to get the right to produce for the firm. It is therefore not possible for the firm to achieve its first best contract under joint ownership.

${ }^{15}$ This assumption allows us to concentrate again on the role of external competitive pressures in the design of the optimal organizational structure of the firm. Clearly all we say will still qualitatively be valid if the increased communication costs between the agent and the firm due to joint ownership are not too large.
} 
each date. Hence the firm's intertemporal total surplus is equal to:

$$
V^{\text {out }}(g)=\frac{\pi / 2}{r+\theta(1)-g}
$$

Result 2: Assume that $\pi / 2-e>\bar{w}$. Under joint ownership: a full degree of information softness can be sustained, ie. $\gamma=1$, and is actually implemented by the firm. ${ }^{16}$

\subsection{KM-policy and the choice of organization}

Let us now consider the optimal choice of organizational form between in-house production (based on a relational employment contract) and joint ownership along a stationary growth path characterized by a given growth rate $g$. The firm decides to share ownership whenever:

$$
V^{\text {out }}(g) \geq V^{\text {in }}(g)
$$

where $V^{\text {in }}$ is given by (22) and (10); and $V^{\text {out }}$ is given by (11). This condition writes as:

$$
\frac{r+\theta(1)-g}{r+\theta\left(\gamma^{i n}\right)-g} \leq \frac{\pi / 2}{\pi-e-\bar{w}}
$$

Hereafter we denote $\tilde{g}$ the growth rate value such that the previous condition holds as an equality. In the appendix we show the following:

Result 3: For $0 \leq g \leq \tilde{g}$, in-house production is preferred while for $\tilde{g} \leq g \leq \bar{g}$, joint ownership is preferred.

The intuition for this result is as follows. The relative cost of joint ownership compared to inhouse production comes from a reduced flow of income in each period. The relative advantage of joint ownership comes from the increased capacity to sustain softness which reduces the probability to be technologically leapfrogged by a competitor. This in turn increases the expected lifetime of the firm. This relative advantage is all the more valuable to the firm that it enjoys a large capitalization effect of its asset value along its life time. The larger the growth rate, the larger the capitalization effect and the larger the relative advantage of the joint ownership organizational form. When the growth rate is small, the capitalization effect is weak and in-house production tends to dominate because of the larger flows of income that the firm receives. Hence this result illustrates how the KM-policy of a firm and its organizational structure in term of ownership are closely interrelated.

Figure 1 depicts the KM-curve, namely $\gamma(g)$ the firm level choice of softness with respect to $g$. For $g<\tilde{g}, \gamma(g)$ is given by condition (22); it is upward sloping because of the capitalization effect under relational contracting. For $g>\tilde{g}, \gamma(g)=1$ under joint ownership. At $g=\tilde{g}$ firms are indifferent ${ }^{17}$ between the two organizational strategies; this is represented by the vertical segment on the figure.

\footnotetext{
${ }^{16}$ Clearly in the presence of communication costs under joint ownership, the previous result would be less extreme, as the firm would benefit from increasing codification in order to reduce these costs.

${ }^{17}$ At $g=\widetilde{g}$ the firm is indifferent and relies on mixed strategy: In-house strategy is chosen with a probability $\lambda$. This
} 


\subsection{Macroeconomic equilibrium}

In this section we solve for the macroeconomic variables which play a key role in the previous analysis, e.g. the growth rate $g$ and the competitive rate $\bar{w}$. The demand for labor has two components: a demand for (supervising) Agents which is always equal to 1 and a demand for (producing) workers, which is, under limit pricing, equal to $Y_{s} / \delta \bar{w}_{s}$. Consequently the labor market clearing condition is:

$$
L=1+Y_{s} / \delta \bar{w}_{s}
$$

Along a stationary growth path, $Y_{t}$ and $\bar{w}_{t}$ grow at the same rate $g$ with $Y_{s}=(1+g)^{s} Y$ and $\bar{w}_{s}=$ $(1+g)^{s} \bar{w}$. It follows that the market clearing condition boils down to : $L=1+Y / \delta \bar{w}$.

Moreover from limit-pricing by monopolies we know that $\delta \bar{w}=P$. But the price of the final good is the numeraire. It follows that the competitive wage is such that $\bar{w}=\delta^{-1}$. Plunging back this term into the market clearing condition, we get $Y=L-1$. From equation (5), the detrended value of cash-flow can be written as $\pi=\left(1-\delta^{-1}\right) .(L-1)$; the net surplus of the firm is thus equal to $S \equiv \pi-e-\bar{w}=(1-1 / \delta)(L-1)-e-\delta^{-1}$. As a consequence the macro equilibrium is characterized by two conditions.

First, the aggregate spillover condition ties down the value of the stationary growth rate to the firm choice of softness of information. It is simply given by condition (8):

$$
g=\underset{(-)}{(\underset{-}{\gamma})} \cdot \log \delta
$$

where $\theta($.$) is given by equation (6).$

Second, the KM-condition associates the firm level choice of $\gamma$ to the aggregate rate of growth. This KM-condition has been studied in the previous section and is given by (12) and (22) which, together with labor market clearing condition, writes as:

$$
\begin{aligned}
\gamma e & =\frac{S}{r+\theta(\gamma)-g} \text { for } g<\tilde{g} \\
\gamma & =1 \text { for } g \geq \tilde{g}
\end{aligned}
$$

where $\tilde{g}$ is given by the equality in condition (12).

On figure 1, the upward sloping curve (KM) corresponds to the KM condition while the downward sloping curve (AS) corresponds to the aggregate spillover curve. We get the immediate result

Result 4: A steady state equilibrium always exists and is unique.

probability must be compatible with the aggregate growth rate $\tilde{g}$ as given by (8). This means that $\lambda$ is such that:

$$
\tilde{g}=\log \delta \cdot[\lambda \theta(\gamma(\tilde{g}))+(1-\lambda) \theta(1)]
$$


Depending on the locus of the KM curve and the AS curve, three different types of equilibria may emerge: a in-house relational equilibrium, a joint ownership equilibrium one and an equilibrium where both types of organizational forms coexist.

\section{Comparative statics and extensions}

In this section we perform various comparative statics relying on graphical support. All computational details are given in the appendix.

\subsection{The Bell-shaped evolution of knowledge codification}

We start our comparative statics exercises with the impact of the long run evolution of Information and Communication Technologies (ICT). As discussed in the empirical literature (see section 3), the spread of ICTs has increased the relative speed of diffusion and transmission of hard information. In our framework (see section 4.3 and condition 2) the knowledge spillover spreads to competitors with a probability $\phi$. We therefore interpret $\phi$ as the efficiency of ICTs.

On figure 2, an increase in $\phi$ has a direct effect on the aggregate spillover curve (AS) which shifts upwards. For a given $\gamma$ an improvement in ICTs' efficiency increases informational spillover and thus the aggregate growth rate of the economy. The effect on the KM-curve is less obvious. First, it unambiguously reduces $(0, \tilde{g})$ which corresponds to the range of the growth rate where in-house production is preferred to joint ownership by firms. The reason is that the increase in ICTs efficiency makes, for a given degree $\gamma$, the cost of information leakage more important. Firms therefore try to reduce codification. This is done by switching from in-house production to joint ownership (where $\gamma=1$ is sustainable). Hence ICTs diffusion promotes joint ownership.

Second, within the in-house regime, there is a creative destruction effect that stands for the fact that an increase in $\phi$ directly increases competitive pressure $\theta$ at the microeconomic level; this in turn makes relational contracts less sustainable for a given $g$. This reduces the degree of soft information $\gamma$ which can be sustained with relational contracts and corresponds to a downward shift of the KM curve within the range $(0, \tilde{g})$.

Summarizing, for low values of $\phi$, an increase in $\phi$ maintains first the economy within the in-house regime but decreases $\gamma$. On the other hand for large values of $\phi$, an increase in $\phi$ promotes the joint ownership regime and increases $\gamma$. As a result, the degree of codification is a bell-shaped curve with respect to the efficiency of ICTs (see figure 3).

Given equations (6) and (AS), the growth rate is given by $g=\left[1+\phi \lambda\left(1-\gamma_{i}\right)\right] \theta_{0} H \log \delta$. An increase in $\phi$ has a direct effect on $g$ through an increase in the scope of informational spillover. But it also has an indirect effect through the endogenous shift in the degree of codification $\gamma$. While the direct effect is always positive, the indirect effect is positive (resp. negative) when the degree of codification (resp. softness) is endogenously promoted by the diffusion of ICTs. Both effects go in the 
same direction as long as the economy remains in the in-house regime. Hence, growth increases with ICTs efficiency. On the contrary, when softness increases, this last feature does not hold anymore along the transition from the in-house regime to the joint ownership regime (a look at figure 3 should convince the reader that the indirect effect dominates). In this transitory regime, growth decreases with ICTs. Finally, when the whole economy has shifted toward joint ownership, information is only under a soft form $(\gamma=1)$ and consequently the increase in $\phi$ has no effect anymore in the growth rate, neither through the direct effect nor the indirect one (see figure 3 ).

All this discussion may be summarized as follows:

Result 5: When $\phi$ increases, the economy switches from a in-house equilibrium to a joint ownership equilibrium. There is a Bell-shaped relationship between the level of information codification $(1-\gamma)$ and $\phi$. Finally, there is a decrease in the aggregate growth rate during the transition phase from the in-house regime to the joint ownership regime (see figure 3) .

This result suggests that ICTs may not necessarily affect positively growth and the scope of informational spillover, when firms adjust endogenously their KM policies. More precisely, the diffusion of ICTs can strengthen the threat of informational spillover so much that in reaction, firms reduce the degree of codification of their know-how. This in turn results in a decrease in aggregate knowledge spillover and a reduced growth rate.

This comparative statics is suggestive of the after war period of economic expansion. The Mass Production regime corresponds, in our framework, to a regime of high growth, high codification, large informational spillover and internal incentives sustained by intertemporal labor contracts whereas the Knowledge based Economy is initially characterized by a improvement of ICTs efficiency, a productivity slowdown, a switch toward more information softness and internal incentives sustained by "empowered" spot labor contracts. It is also somehow consistent with the dramatic change of corporate structures in the late $80 \mathrm{~s}$ and during the $90 \mathrm{~s}$ and the corresponding emergence of vertical disintegration, joint ownership and the erosion of internal labor markets.

\subsection{Growth and scale effects}

Consider now an increase of the stock of skilled workers $H$ available for innovation and R\&D in the economy. It is first worth noting that within our framework, an increase in $H$ drives qualitatively the same results ${ }^{18}$ as an increase in $\phi$. Hence the following result :

Result 6: When the stock of skilled workers $H$ increases, the economy switches from a in-house equilibrium to a joint ownership equilibrium. There is a Bell-shaped relationship between the level of information codification $(1-\gamma)$ and $H$. Finally, there is a decrease in the aggregate growth rate during the transition phase from the in-house regime to the joint ownership regime.

\footnotetext{
${ }^{18}$ All technical details are available from the authors upon request.
} 
A first implication of this result is the fact that the dramatic rise in skilled workforce experienced since the 1970s in many developed countries economies (see Acemoglu 2002 for a discussion) could help explain the switch form Mass production to Knowledge based Economy and the observed transformations in firms' organizations.

More interestingly, the non monotonic comparative statics on the growth rate can be related to the literature on scale effects in endogenous growth models. The first generation of endogenous growth models (Romer 1990, Aghion and Howit 1992, Grossman and Helpman 1991 was characterized by the existence of strong scale effects, namely the fact that the growth rate of an economy is an increasing function of its size or positively related to the stock of resources available for innovation and R\&D. While the very long run history of economic growth appears consistent with the existence of strong scale effects (see Kremer, 1993), they are inconsistent with the relative stability of growth rates in the United States in the 20th century (though the stock of researchers has steadily increased during the same period). Nor do they match stylized recent cross country evidence on growth patterns. Models getting rid of growth scale effects have been developed in the literature. However, either these models are semi endogenous growth models (Jones 1995, Segerstrom 1998) with policy invariant growth rates, either these models maintain the potency of policy to alter long run growth (Young 1998, Dinopoulos and Thompson 1998, Howitt 1999) at the cost of several knife-edge assumptions (for a survey, see Jones 2005).

Our present setting starts with a work-horse model of endogenous growth model generating growth scale effects (putting therefore ourselves in the worst possible situation to reduce them). Still, adding endogenous informational flows (soft versus hard) and their implications for the structure of knowledge spillover in the economy, triggers ambiguous scale effects in growth. In particular, our approach suggests that the strength of scale effects in idea-based growth models can be mitigated by the changing nature of informational flows. Moreover, in our context, this aspect is most likely to occur when we have high diffusion of ICTs technologies and/or an already large stock of research personnel in the economy. These last facts seem to fit relatively well the evolution of OECD countries in the last 40 years, period for which strong scale effects on growth seem to be the least relevant.

Finally, it is worth noting that an additional feature of our current approach is the fact that long run growth (even with ambiguous strong scale effects) can still be affected by policy variables. Indeed, in this setting, growth depends on the nature of informational flows which in turn is a function of institutional and policy variables affecting the environment of the firm (patent laws, ownership structures, labor contracts laws). Therefore, there still remains scope for policy impacts on long run growth in a context somewhat more generic than other scale free endogenous growth models. ${ }^{19}$

\footnotetext{
${ }^{19}$ See in particular Jones (2004) p. 47 for an insighful discussion of these models.
} 


\subsection{Social embeddedness}

In a celebrated book, Saxenian (1996) analyzes the relative performance of Silicon Valley and Route 128 during the 80s. The cornerstone of her analysis is that different cultures and social embededdness within these areas are key variables to explain the observed patterns of organizations (within and between firms) and the observed scope of informational spillover which ultimately explain global performance of each area.

The broad picture is the following. On the one hand, Silicon Valley during the 80s was characterized by a culture ${ }^{20}$ of sharing technical informations which resulted in: i/ a rapid diffusion of knowledge through face-to-face interactions and high labor turnover, ii/ a network of small firms with informal internal organization and close links with their outside suppliers ${ }^{21}$. On the other hand, Route 128 was characterized by a East-coast type of puritan culture where loyalty to the firm and reputation was enforced by a strict social control which resulted in: i/ life long employment and internal labor market ii/ big vertically integrated firms with iii/ high degree of internal codification and hierarchization ${ }^{22}$.

In this section, we briefly discuss how our framework can be amended to capture this link between social embeddedness, knowledge spillover and firms' internal organization. The literature on social networks has highlighted two channels through which social networks affect individual behavior: norms and information: the social norm channel emphasizes how a person's behavior is affected by social and peer pressure within the network while the information channel emphasizes how a person's knowledge depends on the network she belongs to.

The information channel is associated to the fact that social network tend to speed the spread of information, either hard or soft, through face-to-face interactions or social gathering. Analytically, this issue is very much the same as the one discussed above on the impact of ICTs diffusion. Similar results apply and, consequently a culture of information sharing promotes joint ownership and has non monotonic effect on the degree of softness.

The social norm channel relates to the absence of anonymity and the existence of social reputation, which by triggering collective retaliation in case of defection, plays a key role in sustaining cooperation within relational contracts. Hence, the strength and persistence of reputation is in some ways similar to the existence of social pressure. Social pressure obviously affects positively the sustainability of cooperation of the in-house regime with relational contracts between the entrepreneur and the agent. The larger it is, the more stringent is retaliation by society in case of cheating. At the same time

\footnotetext{
${ }^{20}$ see chapter 2 where Saxenian describes the Silicon Valley as a technical community where "informal conversations were pervasive and served as an important source of up-to-date information about competitors, customers markets, and technologies".

${ }^{21}$ See the chapter entitled "Route 128: independence and hierarchy", where it is said that "Route 128s technology enterprises imitated the structure of the traditional mass production corporation. While Silicon's Valley entrepreneurs rejected the corporate practices of the large, established East Coast producers".

${ }^{22}$ See chapter 3 where it is argued that "the managers of Route 128 technology companies [...] created organizations characterized by formal decisionmaking procedures and management styles, loyal long-term employees and conservative workplace procedures."
} 
however, it plays no role under joint ownership. In that case, the hold-up inefficiency due to softness is solved through an increase in the worker spot bargaining power due to a partial transfer of ownership. In the appendix, we present a simple formal extension of these ideas and show that the equilibrium is described by equations similar to (AS) and (KM). Two features can be simply deduced from the analysis. First, the larger the degree of social pressure, the larger the degree of softness which can be sustained for a given growth rate $g$. This corresponds to an upward shift of the KM-curve (see figure 4). Second, the larger the degree of social pressure, the larger the range $(0, \tilde{g})$ of growth rates for which in-house production is preferred to joint ownership. Hence initially, if the economic equilibrium is at $E_{0}$ as shown in figure 4 with joint ownership and full softness of information (ie. $\gamma=1$ ), an increase in social pressures $\beta$, is going to generate a mixed equilibrium along the vertical part of the KM curve, with the fraction of in-house production firms increasing overtime. As $\beta$ goes up, the threshold rate $\tilde{g}$ increases and the equilibrium point moves down along the AS curve. Hence as long as one stays within the mixed production regime, an increase in $\beta$ leads to a decrease in information softness $\gamma$ and an increase in the equilibrium growth rate $g$. This process goes on until we reach a "full in-house" equilibrium where the AS curve intersects the KM curve on its upward sloping part.(as shown for instance by point $E_{1}$ ). Then in this full "in-house" production regime, as the upward sloping part of $\mathrm{KM}$ is shifted up with an increase in $\beta$, the equilibrium point $E_{1}$ moves up along the AS curve, implying now an increase in information softness and a reduction of the equilibrium growth rate $g$.

The preceding discussion can then be therefore summarized in the following result:

Result 7: An increase in the degree of social pressure promotes in-house production. Information softness within the economy is first decreasing and then increasing with the degree of social pressure. Conversely, the growth rate of the economy first increases and then decreases with the degree of social pressure.

\section{Conclusion}

The purpose of this paper has been to investigate one facet of the incentives for organizations to keep soft informational flows or to codify part of them. We emphasize a trade-off shaped by the conflict between internal incentives and external competitive pressures. This provides a natural channel through which competition has some impact on firms organizational structure and informational flows. Because of the consequences for knowledge spillover in the rest of the economy, the nature of informational flows inside organizations has in turn feedback effects on macroeconomic performances and growth.

In order to illustrate these mechanisms in the most simple way, we abstracted from many other facets of the problem of soft information and its diffusion into society. First, we abstracted from technological constraints related to costs of communication and costs of codification. Introducing them would add another margin the firm needs to take into account in its decisions to codify or not some of its knowledge stock. Secondly, our framework consider simple contracting settings and one 
may wish to extend our analysis to more complex environments. For instance, one may think to investigate more systematically the role of social networks and communities to stabilize the problems of opportunism based on soft information. The degree of codification of information inside and across organizations will then be shaped by the structure of social links. In turn, one may expect the structure of social networks to be dependent on the nature of informational flows spreading between them.

Finally, our setting endogenize knowledge spillover in a rather crude way. In particular, we do not provide a precise microfounded description of the process through which hard information gets diffused in the society. This could be due to labor market turnover, migration, industrial spying, informational spillover from regulating parties, etc. Understanding precisely these mechanisms is certainly an important line for future research. We hope that incorporating such extensions into our setting could then be helpful to improve our understanding of the nature of knowledge spillover and their implications in various economic areas like international trade, FDI, economic geography or development. 


\section{REFERENCES}

Acemoglu D., (2002), "Technical Change, Inequality, and The Labor Market", Journal of Economic Literature, volume 40, pp. 7-72.

Acemoglu D., Aghion P., Lelarge C., Van Reenen J., and F. Zilibotti (2007), "Technology, Information and the Decentralization of the Firm", Quarterly Journal of Economics, 122(4), pp.1759-1799.

Aghion, Philippe, Howitt, Peter (1992) "A Model of Growth Through Creative Destruction", Econometrica, Vol. 60(2), pp.323-351.

Ackerman M., V. Pipek and V. Wulf, (2003), Sharing Expertise: Beyond Knowledge Management, MIT Press.

Arrow Kenneth, (1962), "Economic Welfare and The Allocation of Resources for Inventions" in The Rate and Direction of Inventive Activity, R. Nelson, ed. Princeton, N.J., Princeton University Press.

Askhenazy P., Thesmar D. and Thoenig M., (2006), "On the Role between Organizational Practices and New Technologies: The Role of Time based Competition", Economic Journal.

Audretsch David and Maryann Feldman, (1996), "R\&D Spillover and the geography of Innovation and Production", American Economic Review, 86(4), 253-273.

Audretsch David, Max Keilbach and Erik Lehman, (2006), Entrepreneurship and Economic Growth, Oxford University Press.

Autor D., F. Levy and R. J. Murname, 2003, "The Skill Content of Recent Technological Change: An Empirical Exploration", Quarterly Journal of Economics, 118(4).

Baker, Gibbons and Murphy,(2002), "Relational contracts and the theory of the firm", Quarterly Journal of Economics, 117, 39-83.

Battigalli P. and Maggi G., (2002), "Rigidity, Discretion and the Costs of Writing Contracts," American Economic Review, vol. 92(4), pp. 798-817

Baumard P., (1999), Tacit Knowledge in Organizations, Sage, London.

Bertola G., Boeri T. and Cazes S., (2000), "Employment protection and labour market adjustment in OECD countries", International Labour Review.

Burgess S., Propper C. and Wilson D., (2001), "Explaining the Growth in the Number of Applications to Industrial Tribunals, 1972-1997", mimeo Department of Trade and University of Bristol.

Collins, H. (1974), "The TEA Set, Tacit Knowledge in Scientific Networks", Science Studies,4, 165-186.

Davenport T., (1994), "Saving IT's Soul: Human-Centered Information Management", Harvard Business Review, March.

Davenport T., and G. Probst, (2002), Knowledge Management Case Book, Wiley Pub.

Dinopoulos E. and P. Thompson, (1998), "Schumpeterian Growth without Scale Effects", Journal of Economic Growth, 3(4), pp. 313-335.

Drucker Peter F., Post-Capitalistic Society, Harper Collins, New York.

Feldman Maryann and Lichtenberg Frank, (1997), "The Impact and Organization of Publiclyfubded Research and Development in the European Community", Working Paper 6040.

Foray D. and Gault F, (2003), "Measurement of Knowledge Management Practices", , in Measuring Knowledge Management in the Business Sector, chapter 1, ed. by OECD.

Francois Patrick and Joanne Roberts, (2003), "Contracting Productivity Growth," Review of Economic Studies, Vol. 70 (1) pp. 59-85. 
Grossman Gene and Elhanan Helpman, (1991), Innovation and Growth in the Global Economy, MIT Press.

Grossman, S., and Hart, O. (1986), "The Costs and Benefits of Ownership : A Theory of Vertical and Lateral Integration", Journal of Political Economy, Vol 94:4, pp 691 - 714

Hansen MT., Norhia N. and Th. Tierney, (1999), "What's your strategy for managing knowledge", Harvard Business Review, pp.106-116.

Howitt P. (1999), "Steady Endogenous Grwoth with Population and R\&D Inputs Growing", Journal of Political Economy, 107(4), pp. 715-730.

Jones C. (1995), "R\&D- Based Models of Economic Growth", Journal of Political Economy, 103 (4), pp. $759-784$.

Jones C. (2005), "Growth and Ideas", Handbook of Economic Growth.

Keller W.,(2002), "Geographic Localization of International Technology Diffusion", American Economic Review.

Kogut B., and U. Zander, (1996), "What firms do? Coordination, Identity, and Learning", Organization Science, vol.7 (5), pp.502-518.

Kremer M. (1993), "Population Growth and Technological Change: One Million B.C. to 1990", Quarterly Journal of Economics, 108 (4), pp. 681-716.

Kremp E. and Mairesse J, (2003), "Knowledge Management , Innovation and Productivity: a firm level exploration based on french manufacturing CIS3 Data", in Measuring Knowledge Management in the Business Sector, ed. by OECD.

Krugman, Paul, (1991), Geography and Trade, MIT Press.

Levin R.C., A.K. Klevorick, R.R. Nelson, and S.G. Winter, (1987), ”Appropriating the Returns from Industrial Research and Development", Brookings Papers on Economic Activity, 3.

Levin J., (2003), "Relational Incentive Contracts", American Economic Review, June.

Mac Kenzie, D. and Spinardi, G.(1995), "Tacit knowledge, weapons design and the uninvention of nuclear weapons", American Journal of Sociology, vol.101, n²1, 44-99.

Martimort D. and Verdier T., (2004), "The Agency Cost of Internal Collusion and Schumpeterian Growth", Review of Economic Studies, 71, 1119-1142.

Mokyr Joel, (2002), The Gifts of Athena: Historical Origins of the Knowledge Economy, Princeton University Press.

Nelson Richard and Winter Sidney (1982), An Evolutionary Theory of Economic Change, Cambridge, MA , Harvard University Press.

Nickerson Jack, and Zender Todd, (2002), " A Knowledge-based Theory of Governance Choice: A Problem Solving Approach", Mimeo Washington University.

OECD, 2003, Measuring Knowledge Management in the Business Sector, OECD, Paris.

Polanyi Michael (1958), Personnel Knowledge: Towards a Post-Critical Philosophy, London, Routledge.

Quintas P., (2003), "Managing Knowledge in Practice", in Measuring Knowledge Management in the Business Sector, chapter 2, OECD ed., Paris.

Rollet H, (2003), Knowledge Management : Processes and Technologies, Kluwer Academic Publishers.

Romer P. (1990), "Endogenous Technological Change", Journal of Political Economy, 98(5), pp. S71-S102. 
Sanchez R. and A. Heene, (1998), Strategic Learning and Knowledge Management, The Strategic Management Series, Wiley Pub.

Saxenian A, (1996), Regional Advantage: Culture and Competition in Silicon Valley and Route 128, Harvard University Press.

Swartz, N. (2003) 'Boeing acknowledges stolen documents', Information Management Journal, Sept/Oct.

Segerstrom P. (1998), "Endogenous Growth Without Scale Effects", American Economic Review, 88(5), pp. 1290-1310.

Simm D. and J. Ferdinand (2006), "Economic and Industrial Espionage: A Different Perspective on Inter-Organizational Learning", Lancaster University Management School Working Paper n 32.

Thesmar, David and Thoenig, Mathias, (2000) "Creative Destruction and organisation Change", Quarterly Journal of Economics, Vol.115(4), pp.1201-1237.

Von Hippel Eric, (1994), "Sticky Information and the Locus of Problem Solving: Implications for Innovation", Management Science, vol.40, $\mathrm{n}^{\circ} 4$.

Young A. (1998), "Growth with Scale Effects", Journal of Political Economy, 106(1), pp. 41-63. 


\section{Technical Appendix}

\section{A Equilibrium Analysis}

In order to simplify the computations, some assumptions related to the value of parameters are useful.

$$
\begin{gathered}
A_{0}: \log \delta<1 \\
A_{1}: \forall \gamma \in[0,1], \theta(\gamma)<1, \theta^{\prime}(\gamma)<0, \theta^{\prime \prime}(\gamma)<0, \\
A_{2}: \frac{\left(1-\delta^{-1}\right)(L-1)-e-\delta^{-1}}{r+\theta(1)-\theta(0) \log \delta}<e / 3 \\
A_{3}:(\delta-1)(L-1)>2(\delta e+1)
\end{gathered}
$$

Assumptions $A_{0}$ and $A_{1}$ are standard. Assumption $A_{2}$ ensures that a full degree of softness (ie. $\gamma=1$ ) cannot be sustained under in-house regime. Assumption $A_{3}$ ensures that the joint ownership regime is sustainable.

\section{A.1 In-house relational employment contracts}

We make the following informational assumptions. All workers and firms know the identity of firms and employees in all previous periods as long as the firm is still into business. As soon as the employer's project is leapfrogged and disappears, the reputation of that particular firm and all the agents who have been employed by that employer vanish. Both agents go back to anonymity. In other words, we suppose that reputation is project-specific.

At each date, a worker knows all his history of wage payments $\omega_{t}$ and $w_{t}$ and work performances in a given employment relationship. He also knows whether a firm, which he has been employed in any past period, has delivered any promised non contractual payment $\omega_{t}$. At each date, each firm knows the history of past wage payments $\omega_{t}$ and $w_{t}$ paid to all his past workers and also knows the work performances history of its employees whilst employed with the firm.

An employment relational contract specifies that the agent must undertake at each date $t$ the right action on the full set of tasks $[0,1]$ and will receive in exchange a sequence of wage payments $\left(w_{t}\right.$, $\omega_{t}$ ) where $w_{t}$ is the formal component paid when the agent has made the right verifiable actions on the share $(1-\gamma)$ of the hard tasks and $\omega_{t}$ is a promised non contractual wage paid when the agent has made the part of the job on the $\gamma$ remaining non codified tasks. That contract needs to be self enforcing for the two parties. It should therefore satisfy incentive compatibility constraints both for the agent and the firm and the agent's individual rationality constraint.

\section{The agent's incentive constraint:}

Let consider an agent hired at date $t$. At any further date $t+s$, the incentive compatibility constraint of the agent should make sure that the agent derives a higher discounted utility from not shirking 
than shirking. This can be written as:

$$
\begin{aligned}
& w_{t+s}-(1-\gamma) e_{t+s}+\sum_{\tau=1}^{\infty} \frac{(1-\theta)^{\tau}}{(1+r)^{\tau}} \bar{w}_{t+s+\tau} \\
\leq & w_{t+s}+\omega_{t+s}-e_{t+s}+\sum_{\tau=1}^{\infty} \frac{(1-\theta)^{\tau}}{(1+r)^{\tau}}\left[w_{t+s+\tau}+\omega_{t+s+\tau}-e_{t+s+\tau}\right]
\end{aligned}
$$

Assuming that the firm pays the relational contract in each period, when the agent does not shirk, he will earn $w_{t+s+\tau}+\omega_{t+s+\tau}-e_{t+s+\tau}$ with $\tau \geq 0$ as long as the project remains on the leading edge. If he cheats at $t+s$, he undertakes an effort only on the hard share of tasks, faces a cost $(1-\gamma) e_{t+s}$ and receives only the contractual wage $w_{t+s}$. However he will be dismissed by the firm and goes back to the market with a "bad" reputation. ${ }^{23}$ He will get only the reservation wage $\bar{w}_{t+s+\tau}$ as long as the project is on the leading edge for $\tau>0$. . This condition can be written as:

$$
\gamma e_{t+s} \leq \omega_{t+s}+\sum_{\tau=1}^{\infty} \frac{(1-\theta)^{\tau}}{(1+r)^{\tau}}\left\{w_{t+s+\tau}+\omega_{t+s+\tau}-e_{t+s+\tau}-\bar{w}_{t+s+\tau}\right\}
$$

$>$ From Levin (2003) we know that in this environment, the detrended optimal contract is a stationary contract such that $w_{s}=(1+g)^{s-t} w_{t}$ and $\omega_{s}=(1+g)^{s-t} \omega_{t}$. The previous constraint takes then a simpler form:

$$
\gamma e_{t+s} \leq \omega_{t+s}+\sum_{\tau=1}^{\infty} \frac{(1-\theta)^{\tau}(1+g)^{\tau}}{(1+r)^{\tau}}\left\{w_{t+s}+\omega_{t+s}-e_{t+s}-\bar{w}_{t+s}\right\}
$$

This incentive constraint must be true at any date $t+s$ after the hiring. Together with the steady state condition, the agent's incentive constraint becomes then (in detrented value):

$$
\gamma e \leq \omega+\frac{(1-\theta)(1+g)}{(1+r)}\left(\frac{w+\omega-e-\bar{w}}{1-\frac{(1-\theta)(1+g)}{(1+r)}}\right)
$$

Note that when (16) holds, (15) holds for any date $t+s$ after the hiring. Hence if the incentive compatibility constraint is satisfied at the beginning of the relationship, it is also satisfied for periods thereafter. For small values of $r, \theta$ and $g((16))$ becomes:

$$
\gamma e \leq \omega+\frac{w+\omega-e-\bar{w}}{r+\theta-g}
$$

\section{The firm's incentive constraint:}

Let us consider now the incentive compatibility constraint of the firm. Consider again a relationship beginning at date $t$. The firm's incentive constraint corresponds to the case where at any further date $t+s$ after the hiring date $t$, the return to cooperation always dominates the return to cheating. This can be written as:

\footnotetext{
${ }^{23}$ We assume here that the market "sanctions" breaking matches by avoiding to deal with them. Firms will not hire the "deviant" manager as a manager and workers will not want to work as managers in a "deviant" firm. As the reason for the break is because of some cheating on the "tacit" part of the contract, there is always an ambiguity on who is responsible for such a break. In equilibrium, as managers will only receive their reservation payoffs, it is then a weakly dominant strategy for managers and firms in the market to avoid dealing with the parties which separated.
} 


$$
\begin{aligned}
& \pi_{t+s}-w_{t+s}+0 \\
\leq & \pi_{t+s}-w_{t+s}-\omega_{t+s}+\sum_{\tau=1}^{\infty} \frac{(1-\theta)^{\tau}}{(1+r)^{\tau}}\left[\pi_{t+s+\tau}-w_{t+s+\tau}-\omega_{t+s+\tau}\right]
\end{aligned}
$$

At any further date $t+s$, a cooperative firm receives $\pi_{t+s}$ and compensates the agent by giving her the contractual wage $w_{t+s}$ and the non-contractual wage $\omega_{t+s}$. In that case cooperation between the firm and the agent is sustained through time and the relationship lasts with the project. If the firm decides to cheat at date $t+s$, the firm receives $\pi_{t+s}$, gives the contractual wage $w_{t+s}$ to the agent but reneges on the noncontractual wage $\omega_{t+s}$ despite the agent's cooperation. However at any further date $t+s+\tau$, the firm's reputation of being non reliable will spread through the market and no agent will accept to cooperate with this firm; as the degree of codification is fixed only once (at date $t$ ), this means that the firm will be unable to produce correctly and will get zero cash-flow as long as the project is on the leading edge for $\tau>0$.

Using again stationary contracts along a stationary growth path, we can rewrite the firm's incentive constraint in detrended terms as:

$$
\omega \leq \frac{\pi-w}{1+r+\theta-g}
$$

\section{The agent's participation constraint:}

Finally the contract has to satisfy the agent participation constraint. When hired by a firm, the agent undertakes an effort $e_{t}$ for a compensation scheme $w_{t}+\omega_{t}$; his reservation wage (ie. employed as a production worker) is $\bar{w}_{t}$. When the firm is destroyed, with a probability $\theta$, the agent goes back to the labor market. Hence the agent's participation constraint writes as:

$$
\sum_{\tau=0}^{\infty} \frac{(1-\theta)^{\tau}}{(1+r)^{\tau}}\left\{w_{t+s+\tau}+\omega_{t+s+\tau}-e_{t+s+\tau}\right\} \geq \sum_{\tau=0}^{\infty} \frac{(1-\theta)^{\tau}}{(1+r)^{\tau}} \bar{w}_{t+s+\tau}
$$

Along a stationary growth path and with stationary contracts, the agent's participation constraint collapses to:

$$
w+\omega-e \geq \bar{w}
$$

\section{The set of contracts sustaining a given degree of softness $\gamma$}

Consider a given degree of softness $\gamma$ and let us call $\Gamma(\gamma)$, the set of relational contracts $(w, \omega)$ which can sustain cooperation between the agent and the firm for this degree of softness. $\Gamma(\gamma)$ is described in the space $(w, \omega)$ by the constraints $(17)-(18)-(19) ; \Gamma(\gamma)$ is depicted on figure A1. It is not empty as long as the agent's constraint is below the firm's constraint. Simple computations show that it is the case iff:

$$
\gamma e \leq \frac{\pi-e-\bar{w}}{r+\theta(\gamma)-g}
$$

For a given $\gamma$ it is clear that the firm prefers to pay the smallest compensation scheme $w+\omega$. This corresponds to contracts located on the segment $O O^{\prime}$ where the agent's participation constraint is 
binding $^{24}$. Hence as soon $\gamma$ as is sustainable (ie. condition (20) is satisfied) the participation constraint is binding, $w+\omega=e+\bar{w}$, and the firms captures the whole surplus of the relationship. In other words the efficiency wage policy is always dominated by the ex-post compensation policy: for a given $\gamma$, the firm always prefers to incite the agent through $\omega$ rather than through the efficiency wage $(w-e-\bar{w})$. The reason is that the latter one is costly whereas both instruments are perfectly similar in terms of incentive provision [ie. they are substitute either in the agent's incentive constraint (see condition $\mathrm{MIC}$ ) and in the firm's incentive constraint (see condition FIC) $]^{25}$.

The optimal degree of softness for a given growth rate $g \in(0, \bar{g})$

For a given contractual schemes $\left\{w_{s}, \omega_{s}\right\}_{s \geq t}$ the firm's intertemporal value is given by

$$
V_{t}=\sum_{s=t}^{+\infty} \frac{(1-\theta(\gamma))^{(s-t)}}{(1+r)^{(s-t)}}\left[\pi_{s}-w_{s}-\omega_{s}\right]
$$

where the competitive pressure $\theta(\gamma)$ is given by $\theta(\gamma)=f(\phi .(1-\gamma), H)$. Firm maximizes this value with respect to softness $\gamma$ under the constraints (17)-(18)-(19) which ensure that cooperation can be sustained through a well designed labor contracts. In detrented value this means that the firm's objective function writes as:

$$
\left\{\begin{array}{c}
V=\underset{w, \omega, \gamma}{\operatorname{Max}} \frac{\pi-w-\omega}{r+\theta(\gamma)-g} \\
\text { s.t. }\{w, \omega\} \in \Gamma(\gamma)
\end{array}\right.
$$

Let us characterize this optimal $\gamma^{i n}$. From the previous analysis of $\Gamma(\gamma)$, we know that the participation constraint is necessarily binding. If either the agent's or the firm's incentive constraint is not binding, this means the dimension of $\Gamma\left(\gamma^{i n}\right)$ is 2 (see figure A1). Unambiguously this implies that condition (20) cannot be an equality. This last point means that it is possible to find a marginally larger degree of softness, $\gamma^{i n}+\Delta$, which can be sustained by a relational contract (ie. satisfying the condition (20)). As a consequence, $\gamma^{i n}$ could not be the optimal contract. Hence at the optimal $\gamma^{i n}$, all constraints are binding. Using equations (PC)-(MIC)-(FIC), this means that the optimal degree of softness is the largest $\gamma$ such that:

$$
\gamma . e \leq \frac{\pi-e-\bar{w}}{r+\theta(\gamma)-g}
$$

At the optimal degree $\gamma$, all constraints are binding. Hence we get immediately $\gamma e=\omega$ and $w=$ $(1-\gamma) e+\bar{w}$.

Finally from equation (22), we may find out $\gamma(g)$ for $g \in(0, \bar{g})$, ie. the optimal degree of information softness with respect to the growth rate. The degree of softness chosen under in-house production is given by equation (22):

$$
\gamma . e=\frac{\pi-e-\bar{w}}{r+\theta(\gamma)-g}
$$

\footnotetext{
${ }^{24}$ The case where the manager's constraint does not intercept the manager's participation constraint is not possible because this corresponds to the impossible case where:

$$
\frac{\gamma e[r+\theta-g]+e+\bar{w}}{1+r+\theta-g} \geq e+\bar{w}
$$

${ }^{25}$ Basically this result is linked to the fact that agent's reputation does not last more than the firm's reputation. They value the future the same way.
} 
Let denote $R H S(\gamma, g)$ the right-hand-side of (23). Clearly $\frac{\partial R H S}{\partial g}>0$. And $\forall g \in[0, \bar{g}], R H S(0, g) \geq$ $\frac{\left(1-\delta^{-1}\right)(L-1)-e-\delta^{-1}}{r+\theta(0)(1-\log \delta)}$ which is positive according to assumption $A_{0}$. > From assumption $A_{1}$ we get $\frac{\partial R H S}{\partial \gamma}>0$ and $\frac{\partial^{2} R H S}{\partial^{2} \gamma}>0$. Hence $R H S(\gamma, g)$ is increasing and convex in $\gamma$. For a given $g$, equation (23) is depicted in figure A2. Two cases may happen. First: $R H S(1, g)<e$; this means that there is one and only one $\gamma<1$ such that $\gamma e=R H S(\gamma, g)$; this corresponds to the degree of information softness chosen by the firm. Second: $R H S(1, g)>e$; this would mean that a full degree of softness could be sustained; however assumption $A_{2}$ implies that $R H S(1, \bar{g})<e / 3<e ; R H S$ being increasing in $g$, this means that $\forall g \in[0, \bar{g}], R H S(1, g)<e$ and so this case is impossible.

Differentiating (23) we get:

$$
\left(\frac{d \gamma}{d g}\right) / \gamma=\left[\gamma \theta^{\prime}(\gamma)+r+\theta(\gamma)-g\right]^{-1}
$$

A look at figure $A 2$, case 1 , should convince the reader that at the intercept $\gamma$ between the two curves, the slope of $\gamma e$ is larger than the slope of $R H S(\gamma, g)$; hence $\partial R H S / \partial \gamma<e$; this implies that $\theta^{\prime}(\gamma)+\gamma^{-1} \cdot(r+\theta(\gamma)-g)>0$ and so we get $\frac{d \gamma}{d g}>0$.

To sum up this section, we have shown that the implicit $\gamma$ in equation (22) is such that $\forall g \in[0, \bar{g}]$, $\gamma^{\prime}(g)>0$ and $\gamma(g) \in[0, \bar{\gamma}]$ where $\bar{\gamma}<1$.

\section{A.2 In-House vs Joint Ownership}

In the main text we show that joint-ownership is preferred to in-house production when:

$$
\frac{r+\theta(\gamma)-g}{r+\theta(1)-g} \geq \frac{\pi-e-\bar{w}}{\pi / 2}
$$

where $\gamma$ is given by equation (23). Let $W(g)$ and $\Omega$ be respectively the left-hand-side and the righthand-side of condition (25). Assumption $A_{3}$ means that $\Omega>1$.

Consider now a point of "indifference" $\tilde{g} \in[0, \bar{g}]$ where condition $(25)$ is an equality: $W(\tilde{g})=\Omega$. An obvious differentiation gives:

$$
S g\left(W^{\prime}(\tilde{g})\right)=S g\left(\theta(\tilde{\gamma})-\theta(1)+\theta^{\prime}(\tilde{\gamma}) \cdot \frac{d \gamma}{d g} \cdot(r+\theta(1)-\tilde{g})\right)
$$

The sign of the right-hand-side of (26) is ambiguous as $\forall \tilde{\gamma} \in[0,1], \theta(\tilde{\gamma})>\theta(1)$ but $\theta^{\prime}(\tilde{\gamma})<0$ and $\frac{d \gamma}{d g} \cdot(r+\theta(1)-\tilde{g})>0$. However using the definition of $\tilde{g}$ and equation $(24)$, we have: $S g\left(W^{\prime}(\tilde{g})\right)=$ $\operatorname{Sg}\left(\theta(\tilde{\gamma})-\theta(1)+\theta^{\prime}(\tilde{\gamma}) \cdot\left(\Omega \cdot \tilde{\gamma}^{-1}+\theta^{\prime}(\tilde{\gamma}) \cdot \tilde{\gamma} \cdot 2 e / \pi\right)^{-1}\right)$ where $\tilde{\gamma} \in[0, \bar{\gamma}]$. From assumptions $A_{1}, A_{2}$ and $A_{3}$ we get: $S g\left(W^{\prime}(\tilde{g})\right) \geq S g\left(\theta(\bar{\gamma})-\theta(1)+\theta^{\prime}(\bar{\gamma}) \cdot\left(\bar{\gamma}^{-1}+\theta^{\prime}(\bar{\gamma}) \cdot \bar{\gamma}\right)^{-1}\right)$.

But $\theta($.$) being convex, the theorem of intermediate values guaranties that: \forall \bar{\gamma} \in[0,1],(\theta(\bar{\gamma})-$ $\theta(1)) \cdot(\bar{\gamma}-1)^{-1} \leq \theta^{\prime}(\bar{\gamma})$. Consequently we have: $S g\left(W^{\prime}(\tilde{g})\right) \geq S g\left(\theta^{\prime}(\bar{\gamma}) \cdot\left(2-\bar{\gamma}^{-1}+\bar{\gamma}(\theta(\bar{\gamma})-\theta(1))\right)\right.$. By definition, $\bar{\gamma}$ is given by condition (23) with $g=\bar{g} \equiv \theta(0) \log \delta$; hence from assumption $A_{2}$ we get that $\bar{\gamma} \leq 1 / 3$ which implies that: $S g\left(W^{\prime}(\tilde{g})\right) \geq 0$.

This last inequality means that at the point $\tilde{g}$ where $W(\tilde{g})=\Omega$, the function $W($.$) is upward$ sloping and $W^{\prime}(\tilde{g}) \geq 0$; but $W($.$) is continuous and differentiable on [0, \bar{g}]$; consequently we know that there is at most one point $\tilde{g} \in[0, \bar{g}]$ such that $W(\tilde{g})=\Omega$. In that case $\forall g \in[0, \tilde{g}], W(\tilde{g}) \leq \Omega$ and $\forall g \in[\tilde{g}, \bar{g}], W(\tilde{g}) \geq \Omega$. From condition (25) this means that $V^{I N}(g) \geq V^{O U T}(g)$ if $g \leq \tilde{g}$; and $V^{O U T}(g) \geq V^{I N}(g)$ if $g \geq \tilde{g}$ where $\tilde{g}$ is the only point on $[0, \bar{g}]$ where condition (25) is an equality. 


\section{B Comparative Statics}

\section{B.1 ICTs}

The variable $\phi$ impacts the economy through $\theta($.$) which according to equation (6) is given by \theta(\gamma)=$ $\left[1+\phi \lambda\left(1-\gamma_{i}\right)\right] \theta_{0} H$. The equilibrium is characterized by equations (8), (KM) and (12) and is depicted on figure 3 in the main text. For $g \leq \tilde{g}$, the equilibrium writes down as $\gamma e=R H S(\gamma, g, \phi)$ where $g=\theta(\gamma) \log \delta$ and the definition of $\operatorname{RHS}(.,$.$) is given above in the appendix. A straightforward$ differentiation gives:

$$
\frac{d \gamma}{d \phi}=\frac{\partial R H S / \partial \phi}{e-\partial R H S / \partial \gamma}<0
$$

This expression is negative; indeed from the definition of $R H S$ it is obvious that $\partial R H S / \partial \phi<0$; and we show above that $e>\partial R H S / \partial \gamma$.

For $g \geq \tilde{g}$ the joint ownership regime prevails and the equilibrium is characterized by $\gamma=1$ and $g=f(0, H) \cdot \log \delta$. Hence it is obvious that $\phi$ does not impact the equilibrium within this regime.

Finally the threshold value $\tilde{g}$ is such that condition $(25)$ is an equality: $W(\tilde{g})=\Omega$. A straightforward differentiation gives:

$$
\frac{d \tilde{g}}{d \phi}=\frac{-\partial W / \partial \phi}{\partial W / \partial \tilde{g}} \leq 0
$$

This term is negative because we show above that $\partial W / \partial g$ is positive for the value $g=\tilde{g}$ and from the definition of $W($.$) it is clear that \partial W / \partial \phi \geq 0$.

\section{B.2 Social pressure}

As discussed in the main text the social pressure parameter affects the aggregate equilibrium only in the in-house regime. Let $\beta$ be the probability that reputation does not disappear from one period to the other (ie. $1-\beta$ is correspondingly the probability that the agent goes back to anonymity). For a agent; let denote $U_{t}$ the market present value of bad reputation, $\bar{U}_{t}$ the value of anonymity and $U^{\text {coop }}$ the value of cooperating with the entrepreneur. Agent's incentive constraint writes down

$$
\begin{aligned}
& w_{t}-(1-\gamma) e_{t}+\frac{1}{1+r}\left[(1-\beta) \bar{U}_{t+1}+\beta(1-\theta) U_{t+1}+\beta \theta \bar{U}_{t+1}\right] \\
\leq & w_{t}+\omega_{t}-e_{t}+\frac{1}{1+r}\left[(1-\theta) U_{t+1}^{c o o p}+\theta \bar{U}_{t+1}\right]
\end{aligned}
$$

Using the fact that $U_{t}^{\text {coop }}=\sum_{\tau=1}^{\infty} \frac{(1-\theta)^{\tau}(1+g)^{\tau}}{(1+r)^{\tau}}\left\{w_{t}+\omega_{t}-e_{t}-\bar{w}_{t}\right\}$, straightforward computations show that the incentive constraint writes down in detrented terms as:

$$
\omega[1+r+\theta-g]+w \geq e \gamma[r+\theta-g]+e+\bar{w}+(1-\beta)(\bar{u}-u)
$$

For an entrepreneur, let denote $V_{t}$ the market present value of not being on the leading edge, $\bar{V}_{t}$ the value of being on the leading edge with a good reputation ( 0 is clearly the value of being on the

leading edge with a bad reputation, as in the benchmark model) and $V_{t}^{\text {coop }}$ the value of cooperating with the agent. Entrepreneur's incentive constraint writes down

$$
\begin{aligned}
& \pi_{t}-w_{t}+\frac{1}{1+r}\left[(1-\beta)(1-\theta) \bar{V}_{t+1}+(1-\beta) \theta V_{t+1}+\beta(1-\theta) .0+\beta \theta V_{t+1}\right] \\
\leq & \pi_{t}-w_{t}-\omega_{t}+\frac{1}{1+r}\left[(1-\theta) V_{t+1}^{c o o p}+\theta V_{t+1}\right]
\end{aligned}
$$


Using the fact that in detrented value, we have $V^{\text {coop }}=(r+\theta-g)^{-1} \cdot\{\pi-w-\omega-\bar{w}\}, \bar{V}=(r+\theta-$ $g)^{-1} . \bar{v}$, some computations show that the incentive constraint writes down in detrented terms as:

$$
\omega[1+r+\theta-g]+w \leq \pi-(1-\beta) \bar{v}
$$

The agent's participation constraint is not changed and is equal to:

$$
w+\omega \geq e+\bar{w}
$$

As in the benchmark case, the optimal contract for sustaining a given degree of softness is such that the three constraints (27)-(28)-(29) are binding. Hence workers are always paid at their reservation wage and consequently we get $\bar{u}-u=0$ in (27). As a consequence $\gamma$ is given by $\gamma \psi_{0} e=(\pi-e-$ $\bar{w}-(1-\beta) \bar{v}) /(r+\theta(\gamma)-g)$. But $\bar{v}=\pi-e-\bar{w}$. Hence: $\gamma \psi_{0} e=\beta(\pi-e-\bar{w}) /(r+\theta(\gamma)-g)$ and the KM-curve is now given by:

$$
\gamma e=\beta \cdot \frac{S}{r+\theta(\gamma)-g} \text { for } g<\tilde{g}(\underset{(+)}{\beta}) ; \gamma=1 \text { for } g \geq \underset{(+)}{\tilde{g}(\beta)}
$$

The growth rate $\tilde{g}$ corresponding to indifference between in-house production and joint ownership is still given by condition (25) which writes down as: $W(\tilde{g})=\beta \Omega$. Differentiating gives $d \tilde{g} / d \beta=\Omega . W^{\prime}(\tilde{g})$ which is positive as we show previously that $W^{\prime}(\tilde{g}) \geq 0$. Hence we get that $\tilde{g}(\beta)$ is an increasing function. 


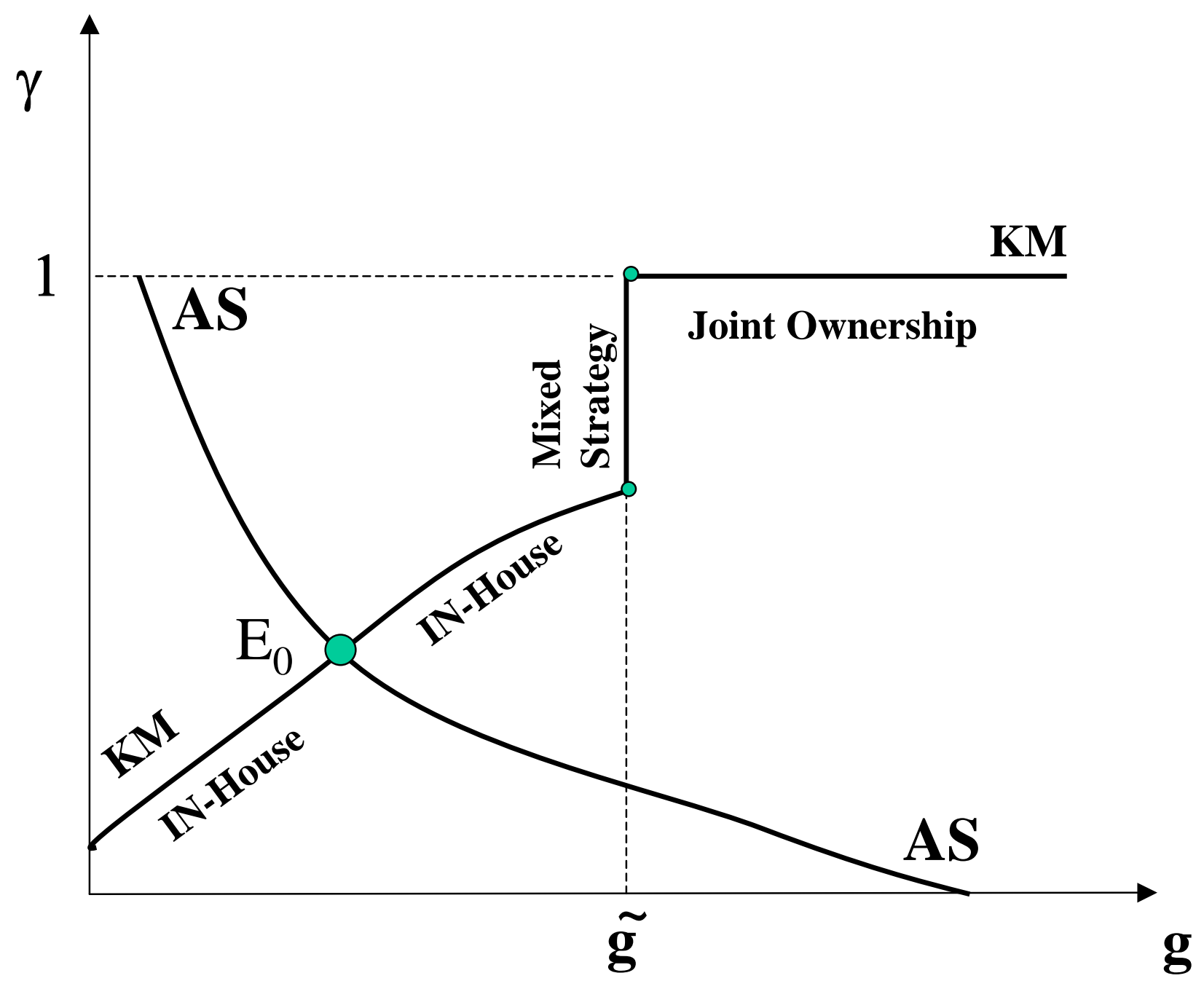

Figure 1: Equilibrium growth and information softness 


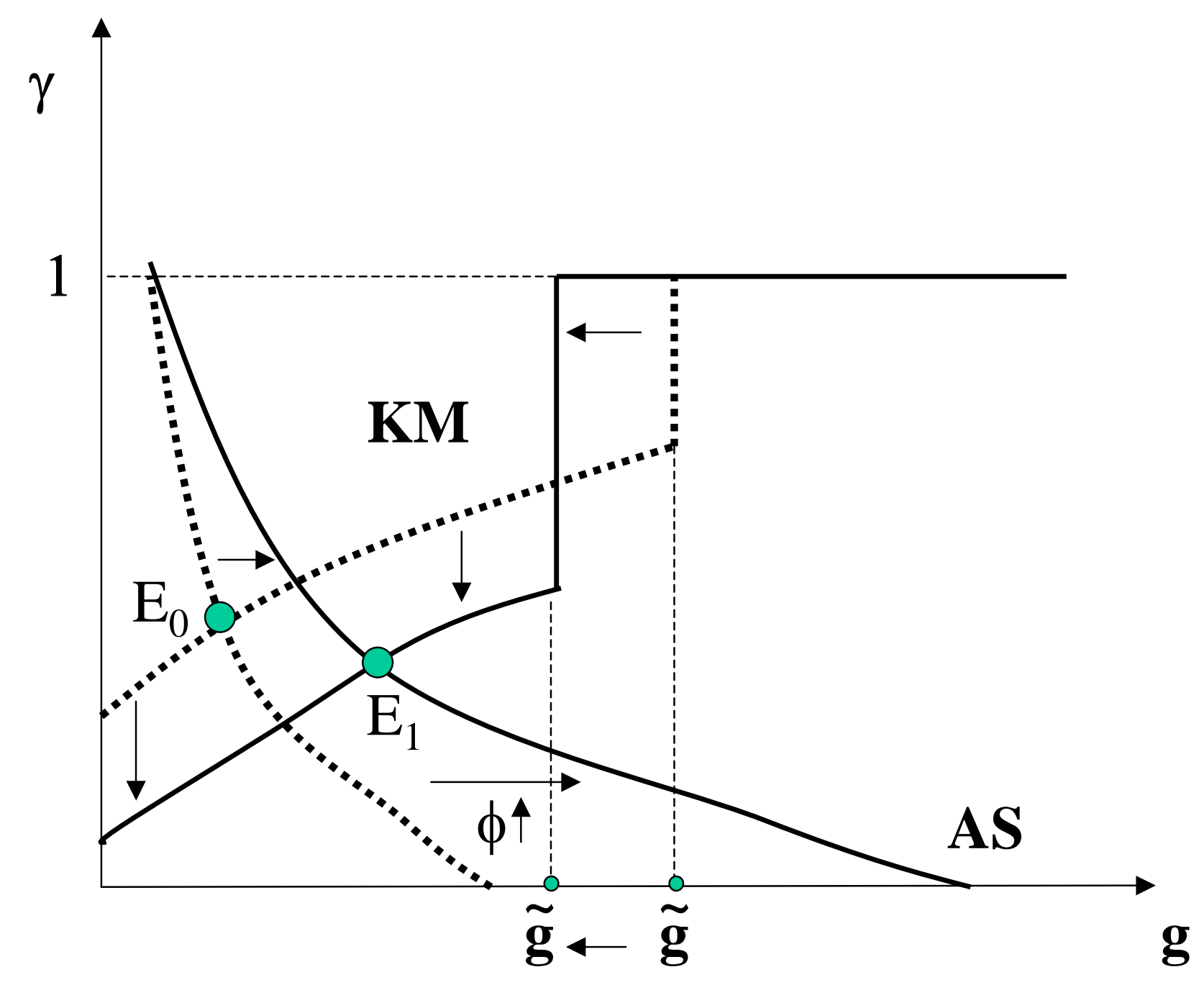

Figure 2: Comparative statics in $\phi$ 
Codification (1- $\gamma)$ and ICTs

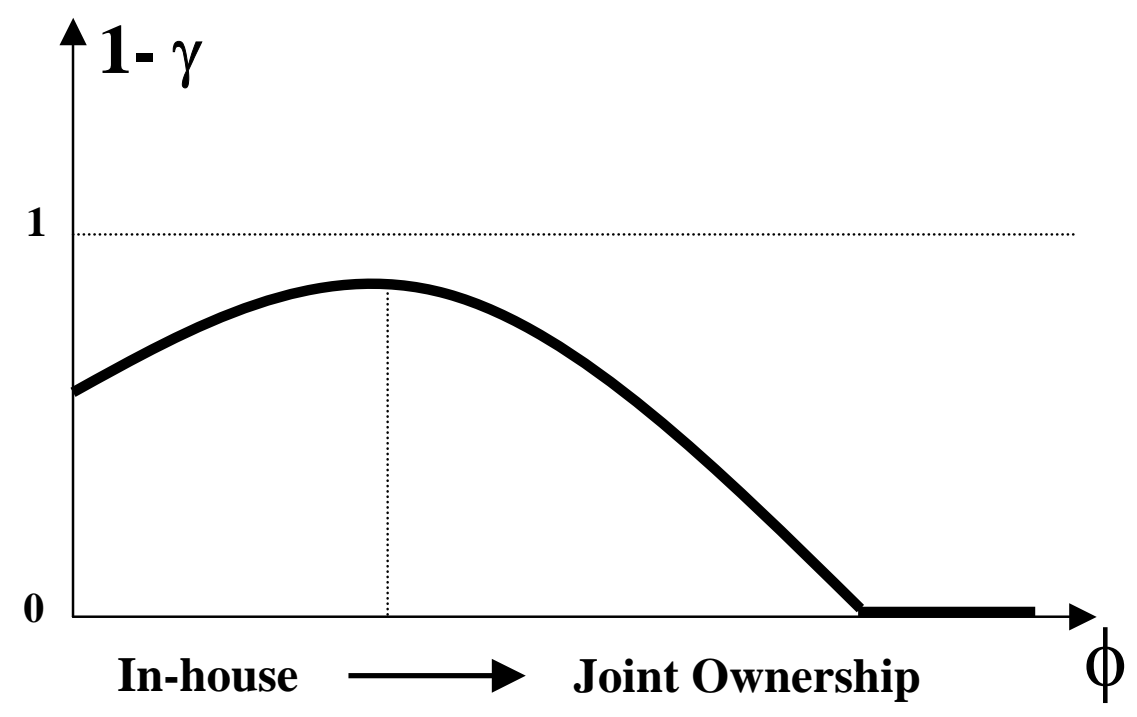

\section{Growth Rate and ICTs}

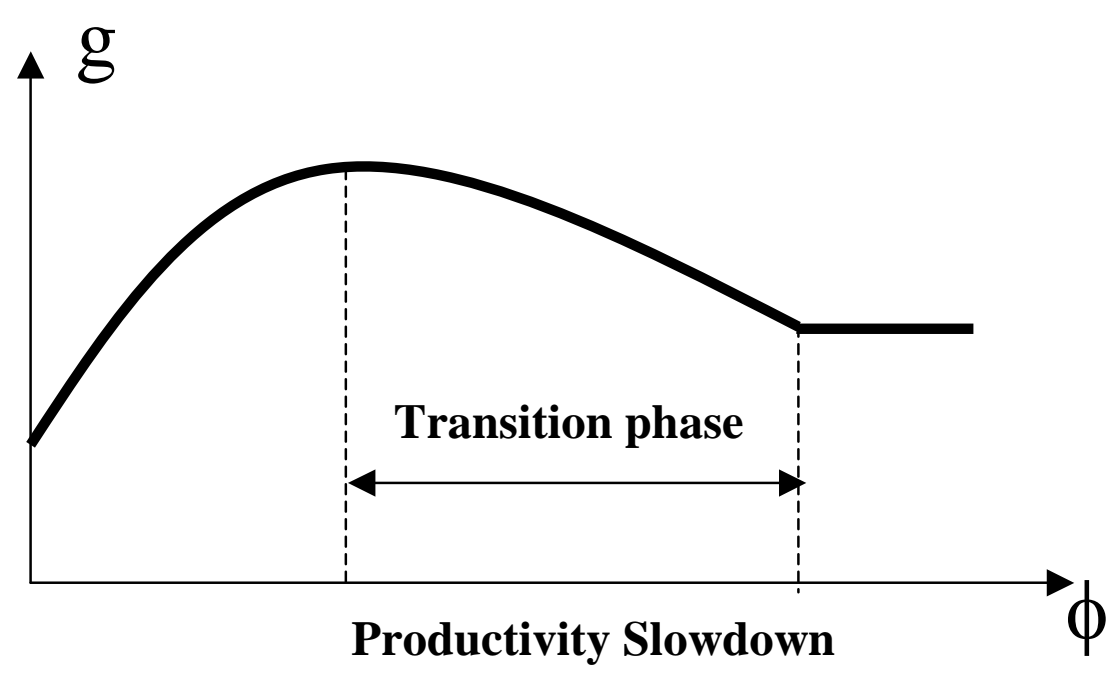

Figure 3: codification, growth and ICTs 


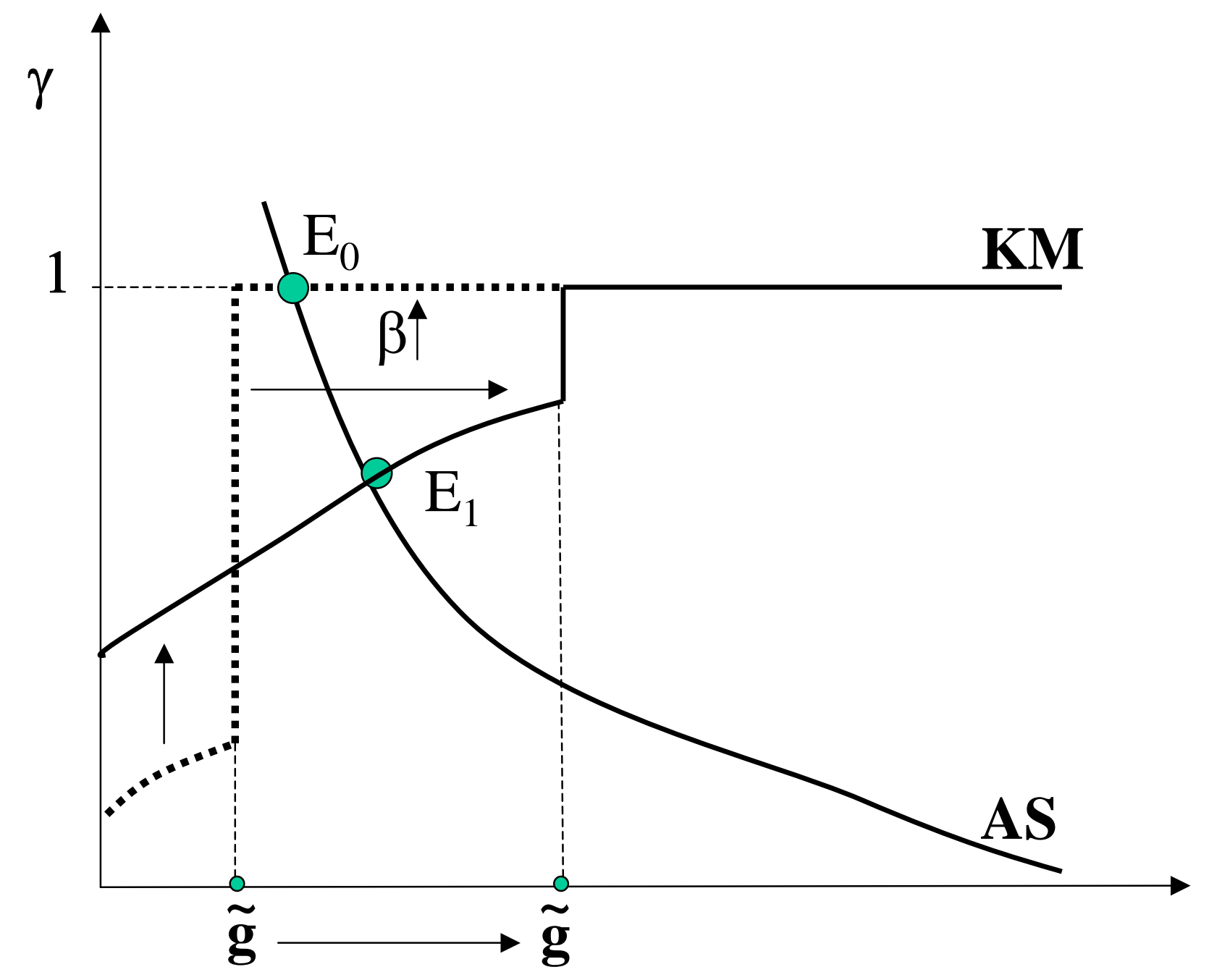

Figure 4: Comparative statics in $\beta$ 


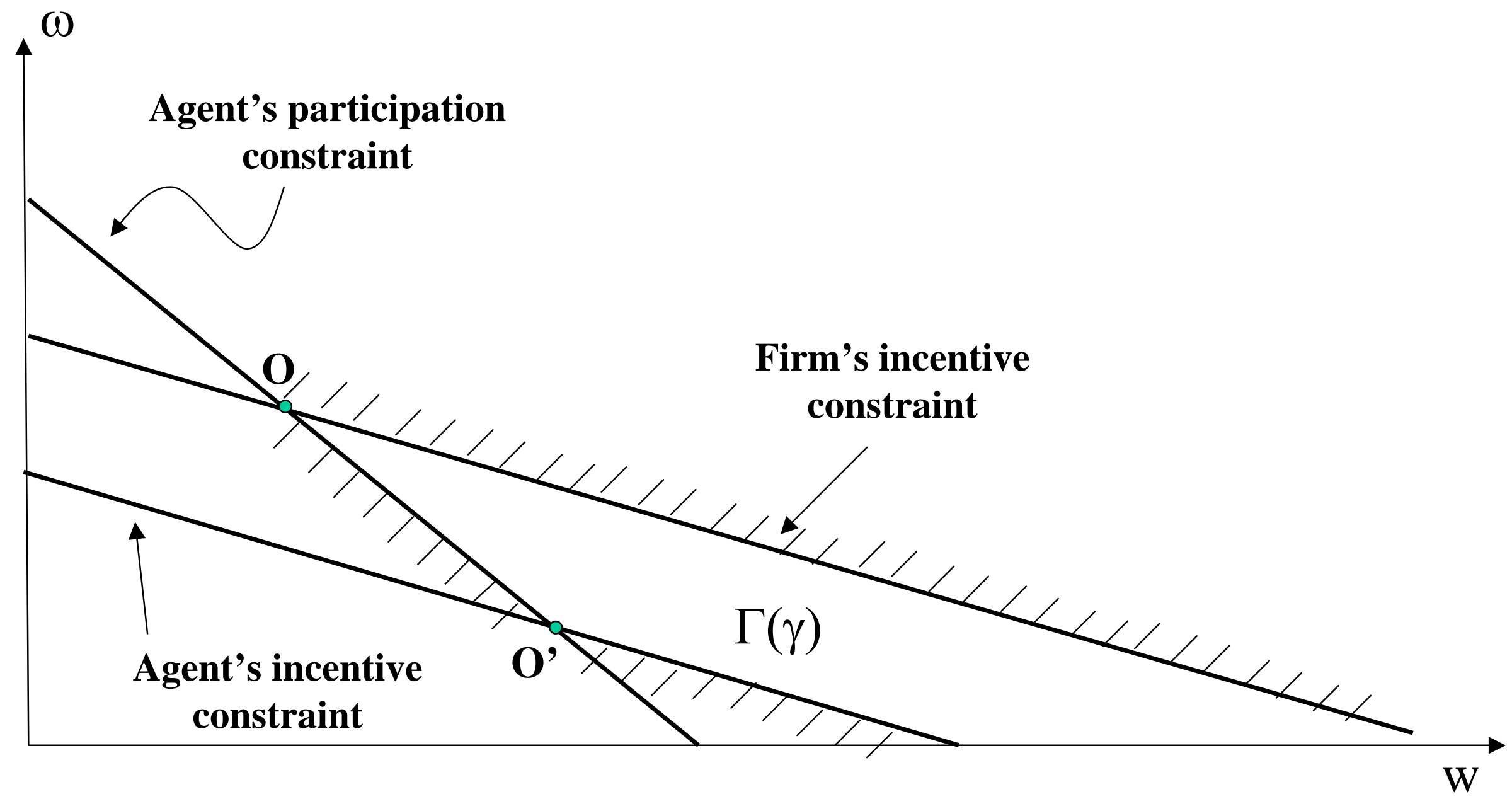

Figure A1: Sustainable contracts' set 


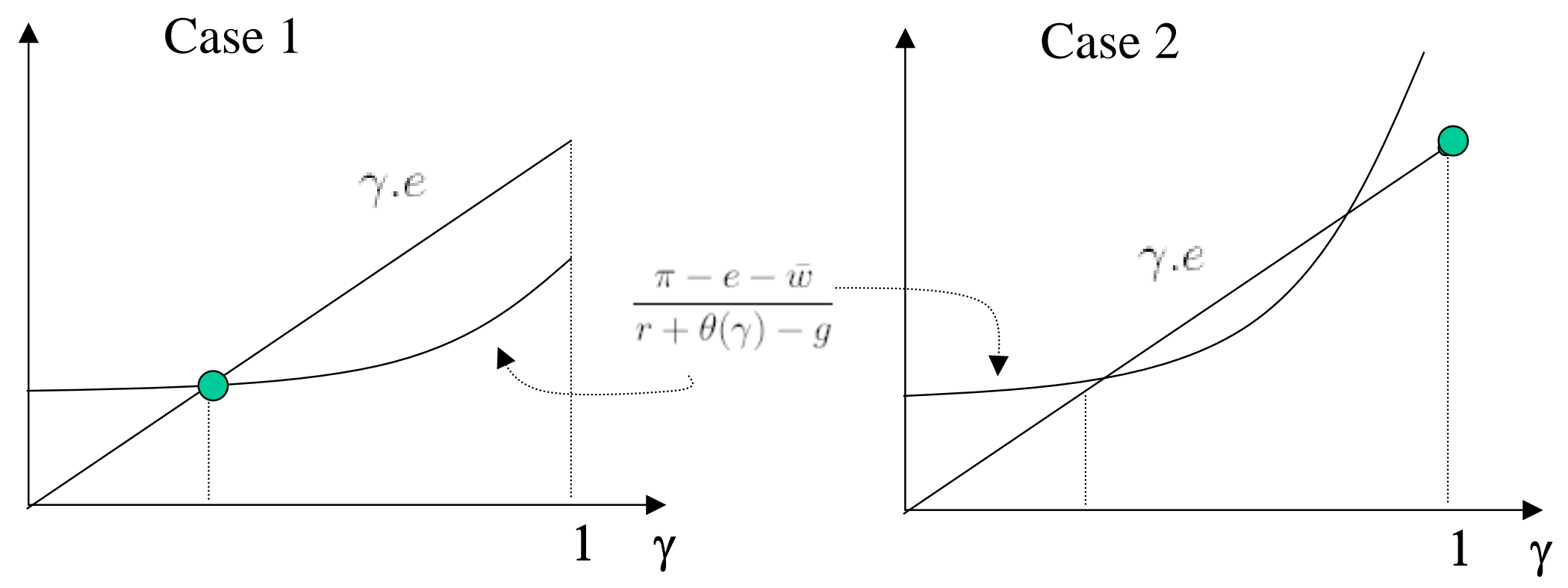

Figure A2: Optimal $\gamma$ under relational contracts:

$$
\gamma . e \leq \frac{\pi-e-\bar{w}}{r+\theta(\gamma)-g}
$$

